\title{
An Ultrastructural Study of the Encapsulation Response of the American Cockroach, Periplaneta Americana
}

\author{
Candace Ann Ennesser \\ Loyola University Chicago
}

Follow this and additional works at: https://ecommons.luc.edu/luc_theses

Part of the Biology Commons

\section{Recommended Citation}

Ennesser, Candace Ann, "An Ultrastructural Study of the Encapsulation Response of the American Cockroach, Periplaneta Americana" (1983). Master's Theses. 3376.

https://ecommons.luc.edu/luc_theses/3376

This Thesis is brought to you for free and open access by the Theses and Dissertations at Loyola eCommons. It has been accepted for inclusion in Master's Theses by an authorized administrator of Loyola eCommons. For more information, please contact ecommons@luc.edu. (c) $($ ) $(9)$

This work is licensed under a Creative Commons Attribution-Noncommercial-No Derivative Works 3.0 License. Copyright (c) 1983 Candace Ann Ennesser 
AN ULTRASTRUCTURAL STUDY OF THE ENCAPSULATION RESPONSE OF THE AMERICAN COCKROACH, PERIPLANETA AMERICANA

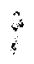 \\ by \\ CANDACE ANN ENNESSER
}

A Thesis Submitted to the Faculty of the Graduate School of Loyola University of Chicago in Partial Fulfillment of the Requirements for the Degree of MASTER OF SCIENCE

BIOLOGY

AUGUST 


\section{ACKNOWLEDGEMENTS}

This thesis was completed under the patient, understanding, and helpful direction of Dr. A.J. Nappi, to whom I will always be thankful. I also wish to thank the other members of my thesis committee, Drs. J.J. Peluso and R.R. Grady for their helpful advice and constructive criticism during my research. I am very grateful to Diane Marshang for her helpful assistance in the begipning of this study. I also wish to thank Mike Silvers for his technical assistance throughout most of this thesis, my family for their patience and understanding, and to all those who have given me advice and aid throughout this time. 


\section{VITA}

Candace Ann Ennesser was born July 25, 1958 in Palos Park, Illinois. Following high school graduation in 1976 she attended Loyola University of Chicago and received her Bachelor of Science degree in biology in 1980.

In 1981 she enrolled in graduate school at Loyola University of Chicago where she studied invertebrate immunology working under the direction of Dr. Anthony J. Nappi and received her masters degree in biology in August of 1983. 
TABLE OF CONTENTS

Page

ACKNOWLEDGEMENTS . . . . . . . . . . . . . . . . . ii

VITA . . . . . . . . . . . . . . . . . iii

Chapter

I. INTRODUCTION . . . . . . . . . . . . . . . 1

II. MATERIALS AND METHODS . . . . . . . . . . 10

Procedure for unaltered nerve cords in host $\underline{P}$.

americana . . . . . . . . . . . . 13

Procedure for viewing freely circulating

hemocytes .. . . . . . . . 13

Hemocyte Terminology . . . . . . . . . 14

III. RESULTS . . . . . . . . . . . . . . . 17

Freely Circulating Hemocytes . . . . . . . 17

Implantation of unaltered nerve cords into $\underline{P}$.

americana . . . . . . . . . . 17

Initial hemocyte response (5- 45 minutes) . . . 18

Capsule Development from 1- 6 hours ....... 21

Full Encapsulation (12- 24 hours) . . . . . 22

IV. DISCUSSION . . . . . . . . . . . . . . . 25

SUMMARY . . . . . . . . . . . . . . . . 46

REFERENCES . . . . . . . . . . . . . . . . . 48

APPENDIX A . . . . . . . . . . . . . . . . 56

Abbreviations ... . . . . . . . . . . 57

APPENDIX B . . . . . . . . . . . . . . . . . 58

Micrographs . . . . . . . . . . . . . . 59 


\section{CHAPTER I}

\section{INTRODUCTION}

Vertebrate immune systems are typically comprised of both humoral and cell-mediated responses. Humoral responses involve the production of specific immunoglobulins, whereas cell-mediated immunity involves the activity of lymphocytes during graft rejection, delayed hypersensitivity reactions, and the enhancement of antigen-antibody interactions. Invertebrate immune systems are not homologous to vertebrate mechanisms for distinguishing foreign materials. It is evident from the many studies of the immune reactivity of invertebrates, especially insects, that cell-mediated reactions are the more prominant type of immune response, (Salt, 1955, 1957, 1959, 1963a, 1965, 1970a,b, 1975; Gupta and Sutherland, 1966; Mercer and Nicholas, 1967; Grimstone et a1. 1967; Peterson; 1968; Nappi, 1970a,b, 1975a,b, 1977b, 1981; Nappi and Stoffolano, 1971; Scott, 1971a; Tripp, 1971; Misko, 1972; Poinar, 1975; Brennan, 1975; Brehelin et al., 1975; Lackie, 1975, 1976, 1979, 1980, 1981,a,b; Lackie and Lackie, 1979; Schmit and Ratcliffe, 1977; Ratcliffe and Rowley, 1979; Ratcliffe and Gagen, 1976; Rowley and Ratcliffe, 1979, 1981). However, against certain microbial agents, 
insects and other invertebrates produce non-specific humoral factors, about which little is presently known(Chadwick, 1967; Lackie, 1980; Jurenka et a1., 1982; Rheins and Karp, 1982; Stynen et al., 1982; Vasta et al., 1982; Hapner, 1983; Ratner et al., 1983; Chain and Anderson, 1983). Although invertebrate immune systems lack both the specificity afforded by antigen-antibody complexes and immunologic memory which provides a more rapid response to foreign invasion after repeated exposure, invertebrates do effectively combat foreign substances.

The cellular immune response of insects, whether occurring in the host as a result of natural infection or by artificial means, is generally carried out by blood cells termed hemocytes. Hemocytes are involved in a variety of functions and constitute the major defense of insects. Some of the known functions of insect hemocytes include, hemolymph coagulation, (Rowley and Ratcliffe, 1981), wound healing, (Day, 1952; Rowley and Ratcliffe, 1981; Yeaton, 1983), nodule formation, i.e. the development of multicellular structures around certain bacteria and protozoa, (Rowley and Ratcliffe, 1981), phagocytosis, (Whitcomb et al., 1974), and encapsulation.

Encapsulation reactions typically involve the aggregation, adhesion, cohesion, and flattening of hemocytes around foreign objects too large to be engulfed by individual 
cells, and the intra- and extracellular deposition of the pigment, melanin, (Salt, 1963a,b, 1970a,b; Poinar, 1969; Whitcomb et al., 1974; Nappi, 1975b). Although there have been numerous studies of cellular encapsulation in insects, fundamental questions regarding the mechanisms of activation of the immune response, and the specificity of the cell interaction, remain unanswered.

of main interest in recent years have been studies of the cellular immune responses associated with host-parasite relationships. Under naturally successful parasitic conditions the parasite is not subjected to any type of immune response that is effective enough to kill the parasite so the host appears immune incompetent. However, artificial implantation of egg or larval parasites which are incompatible with the host elicit usually rapid and strong hemocytic responses resulting in the formation of melanotic capsules. The formation of the pigment melanin, which is in most cases deposited along the foreign surface, has been observed in many studies of encapsulation (Peterson, 1968; Nappi and Streams, 1969; Nappi, 1970b, 1975a,b, 1981; Misko, 1972; Poinar, 1975; Lackie, 1976). Melanins are a group of important pigments formed from the oxidation and polymerization of phenols like tyrosine and dopa through the use of phenoloxidases. Unfortunately, the specific role of melanin in relation to the immune responses of insects is not known. A 
great deal of attention has been focused on the melanization reactions of invertebrates, but there are few studies available which show conclusively that phenoloxidases constitute an important component of the immune system. It has been postulated that pigment formation along the surface of the parasite serves as a barrier to cut off the oxygen supply as well as nutrients vital to the parasite (Salt, 1970a; Lackie, 1981a). From this it would appear evident that implantation of abiotic material into the host cavity would not require the formation of melanin unless an additional role as a possible 'isolator' and disinfectant occurs, (Lackie, 1981a). Misko (1972) felt that only in those defense reactions involving parasites did encapsulation and melanization take place. Therefore, implantation of inert material would result only in encapsulation. Poinar (1975) states that 'simple encapsulation' is the accumulation of host cells around a parasite without secondary melanization. According to Nappi (1973a) the biochemical reactions associated with the melanization of the wasp parasite Leptopilina heteroma (Pseudocoila bochei) constitute an important part of the immune reaction of Drosophila larvae. He suggested the phenoloxidase activity could deplete certain substances from the hemolymph of the host necessary for the development of the parasite, or produce substances toxic to the parasite. Recent studies by Brehelin and Hoffmann (1980), 
Ashida (1981), Soderhall et a1., (1979) and Soderhall (1981), indicate that the prophenoloxidase activating system is probably involved in foreign recognition reactions of arthropods.

Whether a parasite will develop successfully within a potentially immune competent host may depend on either specific failures of the immune system to recognize parasites as foreign, or the ability of some parasites to produce substances that weaken or totally suppress the defense reactions of their hosts, (Lewis and Vinson, 1968; Salt, 1970a,b; Vinson, 1971; Nappi, 1975a,b; Lackie, 1977, 1979). Based on the extensive work of Salt (1970a) and others, previously mentioned, it would appear that the success or failure of insect parasites is dependent upon numerous factors, including the age, stage of development, physiological state, and genetic composition of both parasite and host at the time of infection.

Ultrastructural studies of the encapsulation response of insects have only recently been undertaken. Grimstone et al.(1967) studied the encapsulation of pieces of araldite implanted into the body cavity of the caterpillar, Ephestia kuehniella. At 72 hours after implantation a capsule composed of 50-60 cell layers was formed and three distinct regions of the capsule were identified; an inner layer of necrotic cells consisting of numerous vesicular bodies 
termed cytolysomes, a middle layer of very flattened cells, and an outer layer of apparently unaltered cells which, in later stages of capsule development, became flattened also. Schmit and Ratcliffe (1977) implanted fragments of nerve cord from the locust Schistocerca gregaria into the wax moth Galleria mellonella and noted an immune response after only 5 minutes. One type of hemocyte, termed a granular hemoycte because of its numerous cytoplasmic inclusions, was seen as the first cell type to make contact with the implant. These cells lysed upon contact with the implant and cellular debris was deposited along parts of the implant surface. The lysis of granular hemocytes was followed by adherence of a second type of hemocyte têrmed a plasmatocyte, which formed the majority of the capsule. The morphology of the capsule after 72 hours was similar to that reported by Grimstone et al. (1967). Schmit and Ratcliffe (1977) suggested that the lysis of hemocytes on the surface of the implant was necessary before adherence of intact cells could occur, possibly causing enhanced adherence of subsequent cells.

The cellular immune response elicited by the American cockroach Periplaneta americana to different types of foreign material has been studied by several authors, (Mercer and Nicholas, 1967; Peterson, 1968; Scott, 1971a,b; Misko, 1972; Lackie, 1977 1979, 1981a,b). Mercer and Nicholas (1967) found that capsule formation by $P$. americana in 
response to larvae of the acanthor, Moniliformis dubius, consisted of three distinct regions of cells, and an accumulation of a dark amorphous material considered to be melanin. Initiation of capsule formation was perceived as occurring through the recognition of the surface of the acanthor as foreign by the hemocytes (Peterson, 1968). The stimulus responsible for the numerous aggregation of cells to the implant site is still a mystery. It is conceivable that those cells which lyse upon contact with the implant release some substance into the extracellular matrix which signals other hemocytes to the infected site, (Nappi, and Streams, 1969, 1975a,b; Salt, 1970,a,b; Misko, 1972). Misko (1972) observed the effects of large numbers of living and inert objects on the cellular immune responses of $P$. americana. The injections of multiple live nematodes into the hemocoels of $P$. americana appeared to overwhelm the hosts and death subsequently occurred. The production of melanin was inhibited when the cockroaches were subjected to starvation, and the nematodes, although encapsulated, remained alive. In relation to encapsulation and melanization three conclusions were arrived at by Misko (1972), : (1)encapsulation and pigmentation occur when surfaces are recognized as foreign, (2)immunogen free surfaces,i.e., sterilized surfaces such as latex beads or styrene particles), result only in encapsulation with no pigment formed, 
and (3)surfaces which are seen as non-foreign or 'self' are not encapsulated or pigmented.

When larvae of Hymenolopis diminuta were injected into $P$. americana young larvae recovered after some time were found unencapsulated and embedded in the muscles of the legs and thorax whereas those larvae in later stages of development found in the same areas were encapsulated and melanized (Lackie, 1976). This suggests that perhaps larvae escape encapsulation in remote areas of the body where there is a reduction in the number of circulating hemocytes, and perhaps once the larvae begin to grow, this temporary sanctuary is disrupted and encapsulation follows (Lackie, 1976).

The onset of encapsulation in $P$. americana has been observed as early as 40 minutes following infection (Scott, 1971a). Homologous nerve cord implants of Periplaneta resulted in no encapsulation or deterioration of the nerve cord, however, heterologous nerve cords implanted into Periplaneta resulted in a rapid and strong encapsulation response by the hemocytes after 24 hours (Scott, 1971a).

Although various aspects of the cellular immune response of $P$. americana have been studied previously, (Mercer and Nicholas, 1967; Peterson, 1968; Scott, 1971a; Misko, 1972; Lackie, 1976, 1979, 1980), the early events in the interaction of hemocytes with foreign surfaces in this insect have not been examined in detail. The purpose of 
this investigation was to observe the ultrastructural changes that occurred during the initial stages of hemocyte encapsulation in $P$. americana. 


\section{MATERIALS AND METHODS}

Adult female cockroaches were used throughout this study as both hosts and donors of implanted tissues. A laboratory colony of these insects was maintained at $23-25$ degrees centigrade, and fed raw apples and dog food. Water was supplied ad libitum.

For the purpose of investigating the hemocyte response of $P$. americana to a foreign surface, the ventral nerve cords of several donors were dissected from the specimens in Hanks' balanced salt solution. The surfaces of the nerve cords were altered by fixing the tissues in $1 \%$ glutaraldehyde in $0.2 \mathrm{M}$ sodium cacodylate buffer ( $\mathrm{pH} 7.4$ ) for two hours. For the implantation experiments nerve cords were dissected out of the donor insects, and placed in $1 \%$ buffered glutaraldehyde in buffer for two hours. The nerve cords were then washed in buffer for 90 minutes and placed in $1 \%$ buffered osmium tetroxide for three hours. They were again rinsed in buffer, and placed in sterile Hanks' balanced salt solution for thirty minutes prior to implantation. Small pieces of nerve cord $1-1.5 \mathrm{~mm}$ in length were used as implants.

Adult females used as hosts were removed from the 
rearing chamber and placed in an ice bath for ten minutes to temporarily render them immobile. The insects were then secured on foam rubber blocks (approximately $10 \mathrm{~cm}$ by $5 \mathrm{~cm}$ ) by two rubber bands placed across the body, one placed between the head and thorax and the other at the junction of the thorax and abdomen. When the roaches were fully revived the ventral abdominal cuticle was cleansed with $70 \%$ ethanol. A sterile micro-scalpal was used to make an incision in the intersegmental membrane just posterior to the sixth abdominal sternite. The altered nerve cord fragments were then inserted in the cuticle of the roaches through the incision using sterile forceps. Implants were removed from the hosts at time periods of $5,10,15,30,45$, and 60 minutes, and 6,12 , and 24 hours. A1l implants were removed at the appropriate times and placed in $1 \%$ glutaraldehyde. This whole procedure was repeated three times for each separate time period using fresh hosts for each implantation. A total of 40 Periplaneta were used in this experiment. The implants were then washed in buffer, placed in osmium tetroxide for three hours, washed again in buffer, and brought through a series of dehydrations using $30,50,70,95$, and $100 \%$ ethanol. The implants were then placed in propylene oxide, and subsequently embedded in Epon 812. Silver gray sections approximately 500 um. thick were cut using the MT-5000 ultramicrotome. The sections were then placed on pre-coated grids, 
post - stained with uranyl-acetate and lead citrate for 20 and 5 minutes, respectively, and viewed with a Hitachi $\mathrm{HU}-11 \mathrm{~B}$ transmission electron microscope(TEM).

Unaltered, control implants, which were taken directly from abdomens and implanted for 30 and 60 minutes were removed at the proper times and viewed under scanning electron microscopy (SEM). These control implants were used to insure that the immune response exhibited was a result of the foreign material, and not due to the surgical techniques. Also a whole nerve cord was dissected from a host as a comparison under SEM with the unaltered control implants. A total of five implants were used in this phase of the experiment, two for each time of 30 and 60 minutes and one whole nerve cord for the comparison. For observations with the scanning electron microscope (SEM), the implants were fixed in gluteraldehyde and post-fixed in osmium tetroxide. They were then dehydrated through a graded series of acetone, and processed by the critical point method using liquid carbon dioxide. The implants were then sputter - coated with gold - palladium, and examined with an ISI SX-30 scanning electron microscope. 
Procedure for unaltered nerve cords in host $P$. americana

Unaltered nerve cords, which served as control implants were dissected from the insects and were placed into sterile Hanks' balanced salt solution for thirty minutes prior to implantation. They were fragmented into $1 \mathrm{~mm}$. pieces taking care to only touch the ends, and were placed separately into the abdomens of other Periplaneta through a small incision made with a sterile microscalpal after cleansing the cuticle with alcohol. Implants were taken out at 30 and 60 minutes, placed in $1 \%$ glutaraldehyde for 1-2 hours, and then placed in buffer for 20 minutes. The fragments were then put into $1 \%$ buffered osmium tetroxide for 5 minutes each for ease of identification, placed in buffer for 20 minutes and brought through a series of dehydrations using $30,50,70,95$, and $100 \%$ ethanol for 15 minutes each. Specimens were then put in a critical point dryer, sputter coated with gold palladium, and viewed under scanning electron microscopy, (SEM).

\section{Procedure for viewing freely circulating hemoctyes}

Freely circulating hemoyctes from non - infected, control insects were obtained by bleeding the cut ends of an antenna or leg into Hanks' solution, or by perfusing Hanks' solution into the abdominal hemocoel and collecting the fluid issuing from the cut end of the appendage. The procedure for the latter method was to insert a 26 gauge, sterile 
needle into the intersegmental membrane just posterior to the sixth abdominal sternite, and then to gently inject 1.5 $-2.0 \mathrm{ml}$. of Hanks' solution into the hemocoel. The fluid containing the cells was placed in a centrifuge tube, fixed in $1 \%$ gluteraldehyde for 1 hour, centrifuged at $1500 \mathrm{rpm}$ for 20 minutes, washed and resuspended three times (20 minutes each) in buffer, and then placed in $1 \%$ osmium for 3 hours. The pellet of cells were later rinsed in buffer, dehydrated, and embedded in epon 812 .

\section{Hemocyte Terminology}

Unfortunately, there is presently no universally accepted, comprehensive set of criteria by which insect hemocytes can be classified with ease and certainty, and as a result there exists a confusing synonomy. The lack of agreement in the literature concerning insect blood cell nomenclature has led investigators studying cellular immune responses to use the non-commital term of hemocyte for cells forming capsules around foreign objects.

The literature concerning the hemocytes of cockroaches dates back more than eighty years (Cuenot, 1896,). Most of the research has dealt with two species, the American cockroach, Periplaneta americana, and the oriental cockroach, Blatta orientalis. Despite this long interest, there is presently little, if any, consensus among investigators regarding the morphology, classification, and relative abun- 
dance of the types of blood cells in these insects. Arnold (1972) proposed that the hemocyte complex of Periplaneta and most other species of cockroach, is composed of three basic types of hemocytes; prohemocytes, plasmatocytes, and granular hemocytes. However, considerable uncertainty persists regarding the occurrence and separate designation of other cells considered by some workers to be variants of the granular hemocyte category, namely spherule cells and cystocytes (Gupta and Sutherland, 1965, 1967; Gupta, 1969; Arnold, 1972; Misko, 1972).

For the purpose of this investigation, only two categories of hemocytes are recognized; plasmatocytes (including the prohemocytes of other workers), and granular hemocytes. The use of the term prohemocyte is avoided, since there is no evidence that this cell is indeed the progenitor of all types of hemocytes in $P$. americana. In this study, cells were classified as granular hemocytes solely on the basis of the presence of prominent, typically spherical or elliptical granules in the cytoplasm. These strucures are regarded as diagnostic features of granular hemocytes (Arnold, 1972). Although Arnold (1972) reported that granular hemocytes comprised about $94 \%$ of the hemocyte population of adult Periplaneta, Misko (1972) found plasmatocytes to be more abundant, accounting for up to $70 \%$ of the cells. This disparity may be attributed to different methods of 
preparing and examining cells for total hemocyte counts, and to the fact that Misko classified as plasmatocytes those hemocytes containing a small number of cytoplasmic granules, which Arnold would otherwise classify as granular hemocytes. Unfortunately, Misko (1972) failed to explain how he distinguished quantitatively these two categories of hemocytes, each containing cells with varying numbers of conspicuous, cytoplasmic granules. 
CHAPTER III

\section{RESULTS \\ Freely Circulating Hemocytes}

Hemocytes taken directly from the abdominal cavity of P. americana absent of any experimentally induced immune response were not significantly different morphologically from those hemoyctes observed reacting in the encapsulation response. Hemocytes from control(i.e,non-infected) cockroaches exhibited fewer and smaller protoplasmic extensions, and they were typically spherical, discoidal or fusiform in shape with very large pleomorphic nuclei. Two distinct types of hemocytes were identified, plasmatocytes and granular hemocytes (Figs.1-6), although granular hemocytes were found to be much more abundant.

Implantation of unaltered nerve cords into $P$. americana Figure 7 shows an unaltered nerve cord taken directly from a cockroach and prepared for SEM. Unaltered nerve cords implanted in adult Periplaneta elicited no encapsulation response at 30 or 60 minutes after implantation (Figures 8 and 9). However, large numbers of hemocytes had accumulated at the cut and damaged ends of the implant. These control observations were used as a basis for compari- 
son with altered nerve cords implanted into the hemocoel of Periplaneta.

\section{Initial hemocyte response (5- 45 minutes)}

The cellular encapsulation response of $P$. americana was elicited almost immediately after the implantation of altered nerve cords into the hemocoel. Implants removed five minutes after insertion and examined by TEM showed both lysed and intact hemocytes at or near the surface of the nerve cord (Figs.10 and 11). Nuclei and mitochondria released from lysed cells were readily observed in the extracellular spaces near the surface of the implant. Intact hemocytes in contact with the nerve cord contained numerous, large, electron dense inclusions. These cells, identified as granular hemocytes, were elongated, and their shapes conformed to the surface of the implant. Although a distinct pattern of layering of intact cells against the few lysed cells was observed along small portions of the implant at this initial stage, much of the surface of the implant was devoid of hemocytes, illustrating the early variation in the rate of the encapsulation response.

By 10 minutes virtually all of the hemocytes in contact with the implant had lysed, and a thin layer of cellular debris $5.7 \mathrm{um}$. thick had accumulated against the outer surface of the implant. The plasma membranes of some of these early cohering cells were difficult to distinguish 
(Figure 12). This layer of cellular debris rapidly degenerated so that by 30 minutes recognition of the cellular components was impossible (Fig. 13).

By 15 minutes the hemocytes formed a continuous layer along the majority of the surface of the implant and additional extracellular debris continued to accumulate on the surface (Figure 14). Some of the peripheral hemocytes not yet in contact with the surface of the implant showed signs of lysis (Figures 15 and 16). Phagoctyosis of cellular debris by these cells is indicated by large vacuoles containing debris similar to that seen extracellularly.

Peripheral cells remained intact and began to exhibit a layered pattern against one another (Figs. 17 -19). The appearance of a type of structured inclusion which is honeycombed in shape can be seen at this time in some of the hemocytes. This cellular inclusion was observed in greater numbers in subsequent intervals, but not in hemocytes from control insects.

At 30 minutes most of the debris that had accumulated at the surface of the implant was unidentifiable (Figure 13). Although large numbers of hemocytes had accumulated close to the reaction sites, no distinct cell layers were observed immediately against the surface of the implant. Also at this time period large structured inclusions similar to those seen at 15 minutes could be seen in the cyto- 
plasm of some of the hemocytes. When sectioned longitudinally these structures appeared to be comprised of a number of cylinders. In cross-section some of these cylinders appeared single or double-walled; the entire structure being surrounded by a single membrane. They range in size from 1.6 to 2.6 microns when cut transversely and appeared more numerous at this stage existing from 5 to 13 per cell (Figs. 20 -23). These inclusions were observed intracellularly and extracellularly amid lysed cellular material. Also a fibrous-like inclusion was also observed in one granular hemocyte exhibiting a size of 15 microns in length (Figure 20).

At 45 minutes there was a large accumulation of intact hemocytes on the cellular debris which had surrounded the surface of the implant. The layer of cellular debris between the surface of the implant and the adhering intact cells was reduced in thickness to $1.95 \mathrm{um}$. at this stage (Figure 24). The plasma membranes of the adhering cells, identified as granular hemocytes, were frequently indistinguishable. Some of the cells involved in the developing capsule at this time exhibited small protoplasmic extensions of the plasma membrane, and the majority of the cells were flattened and contained cytoplasmic vacuoles and numerous electron dense inclusions (Figs.25 and 26). Some of the cells involved in the capsule exhibited large vacuoles 
within the cytoplasm giving the cell the appearance of being one large vacuole (Figure 26). These cells contained numerous dense inclusions and mitochondria with plasma membranes remaining intact.

\section{Capsule Development from 1-6 hours}

The growth of the capsule progressed rapidly, so that by one hour six to eight layers of hemocytes were evident, and two distinct regions of the developing cellular capsule could be identified. The first or innermost region was comprised of approximately two to three layers of exceptionally flattened hemocytes with visibly necrotic nuclei (Figure 27). These cells were closely apposed to the cellular debris which surrounded the surface of the implant. A second region (later to be identified as the middle region) was comprised of 4 to 6 layers of hemocytes (Figure 28). Although some of the cells in the second region had begun to lyse, most of the cells were spherical and intact, and loosely associated forming layers. The most peripheral cells in this region of the capsule had large, pleomorphic nuclei, and unlike the cells in the innermost region of the capsule, possessed numerous, small electron dense cytoplasmic inclusions characteristic of normal granular hemocytes (Figure 29).

At 6 hours the capsule was comprised of 12 to 15 lay- ers of cells, and a third or outer region of the cellular 
capsule was evident (Figure 30). The cells of the inner region appeared to form a continous, compact mass with plasma membranes indistinguishable. Except for the presence of numerous small vacuoles around the nuclei, the cells of the inner region were virtually devoid of cytoplasmic inclusions. The presence and arrangement of nuclei made it possible to identify 4 to 6 layers of hemocytes in the inner region of the capsule. The middle region of the capsule (Figure 30, after arrows) was comprised of 6 to 8 layers of hemocytes which were identical in morphology to the cells in the middle region examined at one hour. Although the plasma membranes of the cells were intact the cells showed signs of becoming necrotic. Especially evident was the development of large, cytoplasmic inclusions and the breakdown of cell organelles. The outermost part of the middle region contained cells characteristic of numerous protoplasmic extensions forming what appear to be large vacuoles (Figure 31). The outer region of the capsule contained large, spherical hemocytes that were either free or very loosely arranged to form 1 to 2 cell layers (Figure 32).

\section{Full Encapsulation (12-24 hours)}

By 12 hours the capsule was comprised of approximately 18 layers of hemocytes. In addition to the increase in the number of cell layers, the most visible alteration in the capsule was noted in the middle region where cells were more 
necrotic and compressed than in previous stages (Figure 33).

Fully formed capsules comprised of approximately 22 cell layers were observed at 24 hours. From this time period this increase in hemocyte layers is about 8 times that seen at 45 minutes when the first layer of intact cells was seen. The first cellular region of the capsule was similar to cells seen in the previous time periods (Figures 34-36). The inner region was comprised of approximately 7 ce11 layers. The middle region of the capsule is characteristic of cells which are less flattened and are closer to freely circulating hemocytes in their morphologies (Figure 37) and consist of approximately 10-12 cell layers. Within the cells are numerous dense inclusions and the nuclei are rather small in comparison to the cell as a whole. The outer region of the capsule consisted of cells which were round and very similar to the most peripheral cells seen at the 1 and 6 hour stages. These cells were very loosely aggregated about one another and are not as densely packed as the previous layers and comprised approximately 3 to 4 cell layers. The nuclei were much rounder than the more pleomorphic nuclei seen in freely circulating hemocytes. The cell membranes of these peripheral cells could be easily distinguished and a few dense cytoplasmic inclusions were observed.

The total capsule at 24 hours therefore, consists of 
about 22 layers of hemocytes existing in three morphologically different regions. The compressed layer of now unidentifiable cellular material rests in between these cells and the implant. 


\section{DISCUSSION}

The cellular encapsulation response of Periplaneta americana against foreign material has been studied by Mercer and Nicholas, (1967), Peterson, (1968), Scott, (1971a,b), Misko, (1972), and Lackie, (1975, 1976, 1977, 1979,a,b, 1981,a). However, the initial or early events concerning this type of immune response of $P$. americana have not been examined in detail. Scott (1971a) studied the encapsulation response of $P$. americana against nylon filaments inserted into the hemocoef at 40 minutes, and noted a response comprised of one cell layer around the implant. The fully formed capsule, consisting of numerous hemocytes, was apparent at 24 hours after infection. It is suggested here that the encapsulation response had begun before 40 minutes; however, the early events were not investigated.

In the present study both intact and lysed hemocytes were observed at or near the surface of the implant 5 minutes after its introduction into the abdominal cavity of $P$. americana indicating that the immune response is initiated within 5 minutes of infection. The initial hemocytic response against the implant is cell lysis, and this appears 
to be the first event in the encapsulation response of $P$. americana.

In a similar study, nerve cord fragments of the locust, Schistocerca gregaria were quickly encapsulated 5 minutes after their introduction into the hemocoel of the wax moth, Galleria mellonella (Schmit and Ratcliffe, 1977). Granular hemocytes were believed to be the cell type responsible for the initial recognition of the foreign tissue within the hemocoel since these cells were observed to initially make contact with the implant and subsequently begin to degenerate expelling their organelles into the extracellular matrix. Only after granular hemocyte lysis had occurred on the surface of the implant were intact plasmatocytes observed to adhere and flatten against the nerve cord. According to these authors, plasmatocyte adherence appeared to occur only against those areas of granular cell lys is. This contact and lysis of cells was characterized as the first event of the encapsulation response in $G$. mellonella, followed by subsequent aggregation and adhesion of hemocytes on the implant as the response continued until about 72 hours when the capsule was complete. In the present study, no attempt was made to characterize all of the different types of hemocytes observed; however, cells characteristic of granular hemocytes were seen as the initial cells making contact with the implant followed by adherence of intact 
granular hemocytes on only those areas where cell lysis had occurred. Plasmatocytes were occassionally observed, and although they appeared to play a role in the encapsulation response, they were not viewed in any great numbers.

The source or mechanism that determines initial hemocyte contact has yet to be determined. Contact of hemocytes to the implant surface could be acheived through chance encounters as the cells circulate through the hemolymph (Salt, 1970a). After initial contact is made those cells, due to their enveloping characteristics, flatten against the foreign material and subsequently lyse. This lysed material may then enhance the adhesiveness of other cells coming into contact with the implant although there is no direct evidence for this. This theory would of course exclude the phenomenon of chemotaxis, or the ability of some substance to signal cells to the sight of the foreign material, concerning initial contact of cells to the implant. Salt (1970a) found no evidence for the idea that cells chemotactically migrated to participate in the encapsulation response of Ephestia kuehniella against the ichnuemon wasp Nemeritis canescens. He suggested that if cells were observed to exhibit significant changes in their morphologies before any contact of hemocytes had occurred this may be evidence of a chemotactic factor involved, however, nothing of this nature was noted in his studies. Increased num- 
bers of hemocytes were found in the circulation of parasitized larvae of the fly Orthellia caesarion (Nappi and Stoffolano, 1972), which suggests hemocytes are signaled to vacate areas they inhabit and migrate to the site of infection. In the immune response of Drosophila melanogaster against Leptopilina hetertoma(Pseudocoila bochei) and $P$. mellipes, changes in hemocyte morphologies and behavior were observed before any cell contact was acheived with the foreign surface (Nappi, 1975,a,b). This suggests some type of a stimulus was present having as its source the parasite which may emit some type of substance into the hemocoel. Tripp (1971) believed that insect hemocytes have the ability to recognize surfaces as foreign, and that there are soluble substances within the hemolymph, such as agglutinins, which are capable of exhibiting biological activity. The ability of the hemocytes to discriminate between 'self' and 'non-self' supports the idea that initial contact of hemocytes is not by chance, but by valid recognition of a surface as foreign. It is difficult to determine if any type of chemoctactic stimulus was involved concerning initial contact of hemocytes to the implant surface in the present study. No differential hemocyte counts were performed to determine any change in numbers of circulating hemocytes.

According to Cherbas (1973) an injury factor released 
from damaged epidermis termed hemokinin, or primary injury factor, has been found in the hemolymph of certain insects. Upon damage to the epidermis, this factor is said to be released and subsequently signals other hemocytes to the area of disruption. If hemokinin is present within the epidermis of $P$. americana it could constitute the stimulus for the initial contact and aggregation of hemocytes to the site of the implant.

An interesting observation in this study at 15 and 30 minutes after implantation, was that those cells which are peripheral to the implant and in the area of lysed cellular material had also begun to lyse. From earlier observations at 5 and 10 minutes, it appeared lysis of cells came about only after contact with the implant surface was made. Lysis of peripheral hemocytes such as that seen at 15 minutes in the present study suggests that there may be some type of 'substance' present which is responsible for peripheral cell lysis. It could be that those hemocytes which initially make contact with the implant and then lyse, let escape a 'factor' which would induce lysis of those peripheral cells. Schmit and Ratcliffe (1977) saw no lysis of peripheral hemocytes but concluded that those hemocytes which were peripheral to the foreign implant did release a type of cytoplasmic inclusion into the extracellular matrix. Also observed in the earlier study, were intact plasmatocytes 
adhering to the implant only on those areas of granular cell 1ysis. In the present study, both granular hemocytes and plasmatocytes were involved in initial implant contact and both types were observed to undergo lysis in the early events of encapsulation before any intact cell layers began to form. Subsequent adherence of intact hemocytes to the implant could be enhanced due to the cohesiveness of the cellular material after initial cell lysis of numerous cells occurred against the implant (Lackie, 1981). Lysis of contacting hemocytes may cause the release of a factor which could increase the adhesiveness of the circulating hemocytes causing them to attach to one another to form intact cell layers (Lackie, 1979). Once adherence was acheived, due to the enveloping properties of these cells as time progressed, they would become flattened against one another. Misko (1972) noted that a type of hemocyte, namely cystocytes, are very unstable upon contact with another surface. Cystocytes may participate in the initial response before involvement of granular hemocytes or plasmatocytes. It is conceivable to think that cystocytes could spontaneously rupture when any part of the host integument has been invaded or damaged. If cystocytes do lyse at such an early stage their disruption could easily be overlooked which could explain why they were not observed at any subsequent time intervals. Upon disintegration cytsocytes are known to form a fine precipi- 
tate in the hemolymph of $P$. americana (Wheeler, 1963). This precipitate could also participate in forming the first layer of debris seen in the encapsulation response. It appears that some form of cellular debris must be present along the implant surface before layering of intact cells can take place. This initial layer of debris becomes extremely degenerated by 30 minutes and begins to compress forming what can be seen in later stages as a very thin dense layer of dark material. It would seem possible that cellular debris is needed as an initial 'foundation' for the formation of subsequent cell layers since hemocyte-to-hemocyte adherence in the encapsulation response of $P$. americana to a nylon filament was stronger than hemocyte-to-implant adherence (Scott, 1971a). It could be that lysed cellular material is much more cohesive than intact hemocytes or any intact surface for that matter. Therefore, the cellular debris may act as some sort of 'cement' forming a basis for adherence of hemocytes to the foreign body.

Peripheral to cellular lysis, at 15 minutes intact hemocytes were loosely layered and although these cells were not concentrated as those seen in complete encapsulation responses, (Salt, 1970a,b; Schmit and Ratcliffe, 1977; Lackie, 1979; Mercer and Nicholas, 1967; Misko, 1972; and Nappi, 1975a,b), a distinct conformity of cells to one another was observed. These cells were characteristic of 
granular hemocytes and appeared to be very active phagocytically, exhibiting numerous protoplasmic extensions of the plasma membrane. These cells appeared to be conforming to one another while they were some distance from the implant. This suggests that some stimulus was possibly present which would cause a premature aggregation of hemocytes near the implantation site. It seems feasible that previously lysed hemocytes release some 'substance' as the plasma membranes degenerate which might cause other cells to migrate to the area of activity (Nappi, 1973a,b; Nappi and Stoffolano, 1972). Such a stimulus would explain the appearance of the numerous amounts of cells which appear to be involved at the site at this early stage in the response. Differential hemocyte counts performed on larvae of Drosophila melanogaster parasitized by $L$. heterotoma showed increases in the numbers of circulating lamellocytes, a form of plasmatocyte, quickly after infection (Nappi and Streams, 1969). Whether such a stimulus is present in $P$. americana cannot be determined here because no attempt was made to determine the number of circulating hemocytes before or after infection. The mean number of circulating hemocytes during the last moulting cycle in $P$. americana ranges from 9 to 13 million cells (Wheeler, 1963). One very acceptable idea concerns the surface properties of the hemocyte membranes themselves. Once initial hemocyte attachment had 
occurred, the surface properties of the plasma membranes may undergo changes which would lead them to be recognized as foreign to other cells. Subsequently cells would react to these 'foreign' cells in which event those cells would undergo surface changes (Lackie, 1979). As the thickness of the capsule increased the stimulus would decrease due to the decrease in surface changes of the outermost cells.

From these observations, it is conceivable that chemotaxis is involved concerning the aggregation and lysis of those cells peripheral to the site of infection at least after initial cell contact has been acheived.

Within 45 minutes of implatation, at least three layers of cells were observed adhering to the thin layer of debris deposited along the implant. Schmit and Ratcliffe (1977) observed adherence of intact plasmatocytes after about 20 minutes but only at those sites of granular hemocyte lysis. As stated previously, it may be that intact cells cannot readily adhere to the implant unless some type of debris is present as an intermediate. This could explain the variation concerning encapsulation against the implant where some areas of the implant appeared devoid of any type of amorphous material and subsequent cell layers.

The factor(s) that determine when cell lysis stops and formation of intact cell layers begin is unknown. Granular hemocytes were observed to be responsible for initial recog-

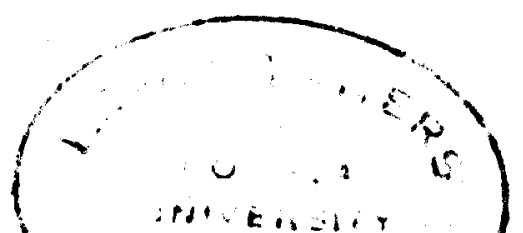


nition of 'non-self' surfaces and only after lysis of these cells did plasmatoycytes adhere to form layers (Schmit and Ratcliffe, 1977). Granular hemocytes, upon lysis, could provide a stimulus for the migration and subsequent aggregation of plasmatoyctes to the site. In the present study, granular hemocytes were seen as the cell responsible for the initial contact with the implant. Although both granular hemocytes and plasmatocytes were observed in the encapsulation response, granular hemocytes were the most prominent type of cell seen. It is possible that a build up of lysed material could provide a kind of inhibitory stimulus which would stop cells from lysing and cause cells to remain intact in layers. This would be supported by the fact that lysis of cells continues until 45 minutes when intact cells begin to form distinct layers.

In the present study, both granular hemocytes and plasmatocytes were seen making contact with the implant and lysing. It would appear both granular hemocytes and plasmatocytes release some type of substance which causes migration of peripheral cells or even those cells not yet present in the circulation in $P$. americana.

Whether granular hemocytes or plasmatocytes are responsible for initial cell contact may not be of functional signifiance since granular hemocytes have been shown to be transformations of plasmatoyctes, (Gupta and Sutherland, 
1966). Although no such transformation in the hemocytes of $P$. americana were observed in the present study, studies performed by Peterson (1968) and Misko (1972) observed plasmatocytes as the predominant cell type according to their classification of these same cells.

Injections of Bacillus cereus bacteria into the hemolymph of $G$. mellonella caused significant decreases in the numbers of circulating plasmatoyctes, (Chain and Anderson, 1982), due to the effects of a substance termed simply, plasmatocyte depletion factor. This evidence supports the idea that plasmatoyctes undergo a migratory change upon introduction of a foreign body into the host. Although it was not determined exactly where these cells aggregated to, a significant change in their behavior was noted. Humoral factors could be involved since subsequent injections of bacterial contaminated hemolymph into second hosts caused decreases in circulating hemocytes in those hosts. If, as previously stated, lysis of cells causes stimulation and subsequent migrations of hemocytes through the release of some factor, it is conceivable that cellular lysis had taken place in the first host and transfer of the substance was acheived upon injection of hemolymph into the second host. The concentration of this substance would be weakened upon injection, supported by the observation that second injections did not deplete circulating hemocytes as effectively 
as in the first host (Chain and Anderson, 1982).

The number of cell layers observed in capsule formation at one hour is on the average two to three times that seen at 45 minutes which suggests once initial layers have formed other cells quickly organize into subsequent layers. It is interesting to note that those cells closest to the implant which appear necrotic are nearly devoid of cytoplasmic inclusions while those more peripheral cells exhibit a moderate amount in their cytoplasm. In $G$. mellonella a type of cytoplasmic inclusion was found to be discharged from intact cells within the capsule (Schmit and Ratcliffe, 1977). It was suggested these inclusions increased adhesion of participating cells. This could explain the absence of cytoplasmic inclusions in those cells closest to the implant in $P$. americana, however, no such release of inclusion from intact cells was noted. If a type of inclusion was released from intact cells, how would this release take place? Permeability of the membrane must be altered somehow to allow transport of these inclusions across the plasma membrane without transport of additional organelles into the extracellular matrix. If such a change in permeability does occur it would suggest a highly specialized function of this cell type. This would add to the not so popular theory that invertebrate hemocytes are specialized cells exhibiting some type of specificity and not carrying out a passive general- 
ized response thought by some to be characteristic of all insect hemocytes. In this later stage of the response, those cells closest to the implant are relatively devoid of cytoplasmic inclusions. The fact that coelescing of cytoplasmic inclusions has been observed extracellularly (Misko, 1972) and abnormally large cytoplamsic inclusions, in relation to cell size, have been seen in this present study as well as by Schmit and Ratcliffe (1977) suggests inclusions are released either through lysis of cells in the early stages or transport of these inclusions across the plasma membrane at later stages.

At the time intervals of 15 and 30 minutes a type of structured inclusion was noted in a significant number of cells. These inclusions appear honeycombed or cylindrical in shape depending on how they were sectioned in the preparation. These organelles appear to be highly organized structures and take up about $40 \%$ of the total cell size. The function(s) of these inclusions is not known. Perhaps there is some relation between these structures and the defense of the insect against foreign invasion. One would guess these inclusions perform an important function because their morphologies are so highly structured and complex in appearance. Baerwald and Bousch (1970) found four different types of inclusions in the cells of $P$. americana, including honeycombed structured inclusions. Although structural dif- 
ferences are clear, it would be difficult to determine without biochemical tests the nature of these inclusions observed in the present study.

At 6 hours cells were extremely flattened and elongate as they rested against the implant. The absence of cytoplasmic inclusions remains a characteristic feature of the innermost cells. These cells appeared to have formed one continuous mass of cells. No plasma membranes were readily seen and cells appeared to retain most of their intracellular organelles although they appeared in differing stages of necrosis. Fusion of hemocytes to form a syncitium was found to occur around a melanized parasite (Nappi and Stoffolano, 1971). However, in experiments concerning the immune response of the catepillar, Ephestia kuehniella, against foreign bodies, no syncitium was reported (Grimstone et al., 1967; Salt, 1970b). Although cells appear intact as evidenced by their intact nuclei, small amounts of amorphous material seemed to be present in between nuclei and this material can be traced to the surface of the implant as if it were being deposited there. It may be that the cells have formed a continous mass and although plasma membranes are absent, the cells become so closely packed or concentrated they can still remain relatively intact. This would explain the ability of material to be continously deposited along the implant with no real apparent lysis of cells or 
nuclei.

The fact that the capsule consists of three different cellular regions at this point in the immune response suggests perhaps a change in the mechanism behind encapsulation had occurred. The first cellular region consisting of elongated, flattened hemocytes found closest to the implant is significantly different than those more peripheral cells which are more similar to free hemocytes. If chemotaxis is involved in initial migration of hemocytes to the site of implantation perhaps the stimulus becomes progressively weakened as cells are added to the capsule. If, as suggested by Lackie, (1979), hemacyte adherence is mediated through recognition of changes in cell surface properties it is conceivable to think that the surface properties change less drastically as each hemocyte layer is added to the capsule. This could be the case since once initial hemocyte attachment is acheived it has been found the adherence of subsequent layers follows very rapidly decreasing the amount of time between hemocyte adherence and change and subsequent adherence of additional hemocytes.

At the 12 and 24 hour stages the hemocytes involved in the capsule closest to the implant appear very necrotic although no true lysis of these cells has taken place. Perhaps some substance vital to the cells' existence is no longer present intracellularly or perhaps 'toxic' substances 
released from lysed cells are taking effect. Of a more basic nature is the fact that transport and exchange of basic nutrients may no longer be possible because cell layers are so concentrated. The presence of a dark material resembling melanin was observed near the implant extracellularly, however, this material could be cellular debris from previously lysed cells in later stages of degeneration. The formation of melanin would appear not to be significant in the defense against an abiotic implant such as an altered nerve cord. Previous studies have determined the advantages of melanin formation when parasites or other live foreign bodies are introduced into the host (Rizki and Rizki, 1959; Peterson, 1968; Nappi and Streams, 1969; Misko, 1972; Nappi and Stoffolano, 1972; Poinar, 1975; Nappi, 1977 a,b, 1981; and Lackie, 1979, 1981a,b). Melanins, which are pigments formed from the oxidation and polymerization of phenoloxidases (Nappi, 1975b) appear to aid the host in the response against live material either by, (1)providing a barrier around the body cutting off the supply of nutrients needed by the implant or by, (2)working as a type of disinfectant against the cells since it is made up of quinones (Lackie, 1981a). If melanin is present in this study, it may possibly play a role in the disinfection of the implant. One hypothesis is that certain types of cytoplasmic inclusions may play a role in the synthesis of melanin. It was postu- 
lated that lysed hemocytes could be the cause of melanin deposition which is found on the surface of the implant (Nappi and Streams, 1969; Salt, 1970a; Misko, 1972). Coelescing of cytoplasmic inclusions has been reported by Misko (1972) after apparent lysis of hemocytes in the immune response of $P$. americana.

Perhaps once a foreign body is introduced into the host, some stimulus may trigger proliferation of a certain type of cytoplasmic inclusion which, upon lysis of the cell, would participate in either melanin production or production of its precursors.

Misko (1972) believed that only in those defense reactions involving parasites did encapsulation and melanization take place. In host reactions concerning abiotic implants only encapsulation would take place illustrating the natural characteristics of insect hemocytes to adhere and envelope a surface once contact was made. On a similar note, Lackie (1981a,b) felt that hemocytes exhibited a graded response in that certain foreign surfaces, such as a parasite, would evoke a greater response (perhaps subsequent melanin production) while abiotic foreign surfaces may be less 'dissimilar' and would stimulate hemocytes to a lesser degree possibly by encapsulation of the material but not being induced to produce melanin. The stimulus responsible for initial recognition by hemocytes would then be mediated through the 
implant (whether live or not) as the foreign surface together with the ability of the hemocytes to recognize such a surface as foreign. Therefore, a foreign object which is recognized as only weakly foreign would cause only a weakened response by the hemocytes. Rizki and Rizki (1959) believed that within certain crystal cells there lies a barrier which separates enzyme from substrate and cells undergo a change in cell permeability so enzyme can react with substrate to form melanin or its precursors. The phenomenon that encapsulation and melanization of some foreign surfaces occur while others are only encapsulated provides a great area of study. It is possible that encapsulation is just a response of hemocytes to adhere to a foreign surface since envelopment is a characteristic of these cells and an added stimulus such as a live parasite would induce those cells which are destined to be involved in the response, as a general defense mechanism, to begin synthesis of the necessary melanin precursors. Perhaps these substances are not present in sufficient quantities beforehand to be effective in melanin production unless a stronger stimulus such as a live parasite is present. Larvae of $G$. mellonella when injected with bacteria show an increase of circulating hemocytes exhibiting phenoloxidase activity (Pye and Yendol, 1972). This could support the theory that substances needed for melanization are stimulated to be produced upon introduction 
of a strong enough stimulus such as a live bacteria.

The early observations of the encapsulation response of $P$. americana offers some very interesting areas of study. Although the early events of the response have not been studied previously the observation that initial hemocyte contact begins with adherence and lysis of mostly granular hemocytes may still not constitute the first event in encapsulation. Perhaps there is some type of injury factor within the epidermal cells (Cherbas, 1973) which would be the initiator. Whether recognition of hemocytes to foreign material is of a specific nature or not remains to be determined. However, Lackie (1975) suggests recognition of foreign substances is dependent upon how 'dissimilar' the foreign surfaces are to the hemocyte surface so that different surfaces would elicit different responses. This would mean that the surface receptors, if present, on the hemocytes would be specific to a certain degree. Humoral factors may be involved in recognition and subsequent defense against foreign material in $P$. americana. Rheins and Karp (1982) demonstrated that a humoral factor which is similar to a precipitating antibody-like molecule and is protein in nature can be induced upon injection of the complex Honeybee venom and Western Cottonmouth Moccasin venom. Upon second injections this humoral factor exhibited a classic anamnestic response. Lectins have also been implicated as links 
between hemocyte surfaces and 'non-self' particles presumably functioning as a type of surface receptor for that cell (Vasta et al., 1982).

Subsequent aggregation and adhesion of hemocytes to the implant site could be mediated through some signal from previously lysed cells through release of some migratory factor. Changes in surface properties of those cells already involved in adhesion could also stimulate circulating cells to adhere upon recognition of the former cells as 'non-self'. According to Nappi (1973b) it is conceivable that aggregation of hemocytes following initial contact is caused by a hormonal imbalance such as abnormal uptake of host metabolites by hemocytes directly involved in the reaction.

Subsequent to the formation of intact cell layers, the capsule appears to become one large mass in the peripheral regions suggesting the plasma membranes have degenerated. The mechanism which determines when intact layers begin to form and lysis stops may involve a build up of substances from lysed cells, such as an inhibitory factor present which stops cells from lysing. Therefore, the rest of the cells destined to be involved in the response would remain intact. At the end of the 24 hour period three regions of capsule formation are apparent with the initial layer of cellular debris or cohesive layer,(1)a continous cellular mass 
characteristic of necrotic cells with extremely abnormal nuclei,(2)a region of flattened, elongated hemocytes with visible plasma membranes and, (3) a layer of more typical hemocytes resembling freely circulating cells. The presence of melanin seen in small amounts, appears to be of little significance in this reaction since most of the melanin production observed is in relation to live objects rather than dead (Misko, 1972; Nappi, 1975a,b).

It is not unreasonable to think that if one of these defense mechanisms of $P$. americana is at work the others could also be at the same time. Therefore, it is conceivable that a 'system' of mechanisms is involved, all of which may depend on events of each other in order to be totally effective. 


\section{Summary}

The hemocytic response of $P$. americana was observed as early as five minutes after implantation of a piece of altered nerve cord into the abdominal hemocoel. The first event in the encapsulation response was the lysis of granular hemocytes at the surface of the implant. Subsequently, cells in the vicinity of the implant, but not yet in contact with its surface, also lysed. The lysis of hemocytes, which continued until approximately 45 minutes after implantation, resulted in the accumulation of cellular debris on the surface of the implant. A cellular capsule, comprised of 22 layers of hemocytes was formed around the implant at 24 hours. At this time three distinct regions of the cellular capsule were identified; an inner region comprised of 4 to 7 layers of flattened, necrotic cells, a middle region of about 12 layers, and an outer region of about 2 cell layers. Granular hemocytes with a few plasmatocytes were observed as the cell type making up the capsule layers. At 6 hours the first cellular region of the capsule appeared as one continuous mass of compressed cells. The production of melanin did not appear to be of major importance in the encapsulation of abiotic foreign material in $P$. americana.

The stimulus for the aggregation and initial cell lysis of granular hemocytes against the surface of the implant is not known. Chance encounters of circulating cells 
with the implant may be important in initiating the cellular immune response. Chemotactic stimuli may be involved in the response, especially during the later stages when hemocyte aggregation results in the development of a multilayer capsule.

The factor(s) responsible for terminating cell lysis and hemocyte aggregation is also not known. Perhaps the progressive build up of cell debris and the addition of numerous hemocyte layers around the implant serve to sequester the stimulus.

A type of structured inclusion was observed in some granular hemocytes at 15 and 30 minutes but not observed in any uninfected blood cells. The origin and function of these inclusions is presently not known. 


\section{REFERENCES}

Arnold, J.W. 1972. A comparative study of the haemocytes (Blood cells) of cockroaches (Insecta: Dictyoptera: Blattaria), with a view of their significance in taxonomy. Can.Ent., 104:309-348.

Ashida,M.1981. A cane sugar factor suppressing activation of prephenoloxidase in hemolymph of the silkworm, Bombyx mori. Insect Biochemistry, 11:57.

Baerwald,R.J. and Bousch,G.M.1970. Fine structure of the hemocytes of Periplaneta americana (Orthoptera:Blattidae) with particular reference to marginal bundles.J. Ultrastructural Research.,31:151-161.

Brehelin,M. and Hoffmann, J.A. 1980. Phagoctytosis of inert particles in Locusta migratoria and Galleria mellonella. Study of ultrastructure and clearance. J. Path.,26: $65-73$.

Brehelin,M., Hoffman,J.A., Matz,G. and Porte,A. 1975.

Encapsulation of implanted foreign bodies by hemocytes in Locusta migratoria and Melolontha melolontha. Cell Tiss. Res., 160: 283-289.

Brehelin,M. and Hoffmann, J.A. 1980. Phagocytos is of inert particles in Locusta migratoria and Calleria mellonella Study of ultrastructure and clearance. J. Insect Physiol., 26: 103 .

Brennan, B. 1975. Resistance of Moniliformis dubius to defense reactions of the American cockroach, Periplaneta americana. J. of Invert. Path.,26: 65-73.

Chadwick,J.S. 1967. Serological responses of insects. Feder ation Proceedings, 26(6): 1675-1679. 
Chain,B.M. and Anderson,R.S. 1982. Selective depletion of the plasmatocytes in Galleria mellonella following injection of bacteria. J. of Insect Physiol.,29: $377-384$.

Chain, B.M. and Anderson,R.S. 1983. Inflammation in Insects: The release of a plasmatocyte depletion factor following interaction between bacteria and haemocytes. J. Insect Physiol., 29(1): 1-4.

Cherbas, L. 1973. The induction of an injury reaction in cul tured hemocytes from Saturniid pupae. J.of Insect Physiol., 19: 2011-2023.

Cuenot,L. 1896. Etudes physiologiques sur les Orthopteres. Arch.Biol., 14: 293-336.

Day,M.F. 1952. Wound healing in gut of the cockroach Periplaneta. Aust. J. Sci. Res. (B) .,5: 282-289.

Grimstone, A.V, Rotheram,S. and Salt,G. 1967. An electron microscope study of capsule formation by insect blood cells. J. Cell Sci.,2: 281-292.

Gupta,A.P. 1969. Studies of the blood of Meloidae (Coleoptera)1. The hemocytes of Epicauta cinerea (Forster) and a synonomy of hemocyte terminologies. Cytologia,34; $300-344$.

Gupta,A.P. and Sutherland,D,J. 1965. Observations on the spherule cells in some Blattaria(Orthoptera). Bull. Ent. Soc. Am., 11: 161 .

Gutpa,A.P. and Sutherland,D.J. 1966. In Vitro transformations of insect plasmatocytes in some insects. J. Insect Physiol.,12: 1369-1375.

Gupta,A.P. and Sutherland,D.J. 1967. Effects of sublethal doses of chlordane on the hemocytes and midgut epithelium of Periplaneta americana. Ann. of the Ent. Soc. of $\operatorname{Am} ., 61(4): 910-918$. 
Hapner,K.D. 1983. Haemagglutinin activity in the hemolymph of individual Acrididae (Grasshopper)specimens. J. Insect Physiol.,29(1): 101-106.

Jurenka,R. Manfredi,K. and Hapner,K.D. 1982. Haemagglutinin activity in Acrididae (Grasshopper)haemolymph. J. Insect Physiol.,28(2): 177-181.

Lackie,J.M. 1975. The host specificity of Moniliformis dubius (Acanthocephala). A parasite of cockroaches. Inter. J. Parasit.,5: 301-307.

Lackie,A.M. 1976. Evasion of the hemocytic defense reaction of certain insects by larvae of Hymenolopis diminuta (Cestoda).Parasitology,73: 97-107.

Lackie, A.M. 1977. Cellular recognition of non-self in insects. In: Developmental Immunobiology J.B. Solomon and J.D. Horton(eds, Amsterdam: Elsevier/North Biomedical Press,p.75-81.

Lackie,A.M. 1979. Cellular recognition of foreignness in two insect species, the American cockroach and the desert locust. Immunobiology,36: 909-914.

Lackie,A.M. 1980. Invertebrate immunity, Parasitology.80: 393-412.

Lackie,A.M. 1981a. Immune recognition in insects. Developmental and Comparative Immunology,5: 191-204.

Lackie,A.M. 1981b. Humoral mechanisms in the immune response of insects to larvae of Hymenolepis diminuta (Cestoda). Parasite Immunology, 3: 201-208.

Lackie,A.M. and Lackie,J.M. 1979. Evasion of the insect immune response by Moniliformis dubius (Acanthocephala): further observations on the origin of the envelope Parasitology,79: 297-301. 
Lewis,W.J. and Vinson, S.B. 1968. Immunological relationships between the parasite Cardiochiles nigriceps vierick and certain Heliothis species. J. Insect Physiol., 14: 613-626.

Mercer,E.H. and Nicholas,W.L. 1967. The ultrastucture of the capsule of the larval stages of Moniliformis dubius (Acanthocephala) in the cockroach, Periplaneta americana. Parasitology,57: 169-174.

Misko, I.S. 1972. The cellular defense mechanisms of Periplaneta americana. Ph.D. Dissertation. The Australian National University.

Nappi,A.J. 1970a. Hemocytes of larvae of Drosophila euronotus (Diptera: Drosophilidae). Annals of the Ent. Soc. of $\mathrm{Am} ., 63(5)$ : 1217-1224.

Nappi,A.J. 1970b. Defense reaction of Drosophila euronotus larvae against the hymenopterous parasite Pseudocoila bochei. J. of Invert. Path., 16: 408-418.

Nappi,A.J. 1973a. The role of melanization in the immune reaction of larvae of Drosophila algonquin against Psuedocoila bochei. Parasitology,66: 23-32.

Nappi,A.J. 1973b. Hemocytic changes associated with the encapsulation and melanization of some insect parasites. Exp. Parasit.,33: 285-302.

Nappi,A.J. 1975a. Insect hemocytes and the problem of host recognition of foreigness. In: Contemporary Topics in Immunobiology. E.L. Cooper(Ed.). New York: Plenum Publishing Co.,p.207-224.

Nappi,A.J. 1975b. Parasite encapsulation in insects. In: Invertebrate Immunity mechanisms of invertebrate vector parasite relations. K. Maramorosch and R.E. Shoppe(Eds.). New York: Academic Press., 293-325. 
Nappi,A.J. 1977a. Factors affecting the ability of the wasp parasite Pseudocoila bochei to inhibit tumorigenesis in Drosophila melanogaster. J. Insect Physiol.,23: $809-812$.

Nappi,A.J. 1977b. Comparative ultrastructural studies of cellular immune reactions and tumorigenesis in Drosophila In Comparative Pathobiology. L.A. Bulla, Jr. and T.C. Cheng(Eds.) New York: Plenum Press,p.155-188.

Nappi,A.J. 1981. Cellular immune response of Drosophila melanogaster against Asobara tabida.

Parasitology, 83: $319-324$.

Nappi,A.J and Stoffolano, J.G. Jr. 1971 Heterotylenchus autumnalis hemocytic reactions and capsule formation in the host, Musca domestica. Exp. Parasit.,29: 116-125.

Nappi,A.J. and Stoffolano,J.G.,Jr. 1972. Haemocytic changes associated with the immune reactions of nematode infected larvae of Orthellia caesarion. Parasitology, 65: 295-302.

Nappi,A.J. and Streams,F.A. 1969. Haemocytic reactions of Drosophila melanogaster to parasties Pseudocoila mellipes and $P$. bochei. J. Insect Physiol.,15: 1551-1556.

Peterson,L.G. 1968. Cellular immune responses of insects to foreign tissue implants. Master's Thesis. University of Illinois.

Poinar,G. 1969. Arthropod immunity to worms. In: Immunity to Parasitic Animals G.J. Jackson, et.al. (Eds.) New York: Appleton-Century-Rofts.,p.173-210.

Poinar,G. 1975. Insect immunity to parasitic nematodes. In: Contemporary Topics in Immunobiology 4. E.L. Cooper(Ed.)New York: Plenum Publishing Co.,p.1167-1177.

Pye,A.E. and Yendol,W.G. 1972. Hemocytes containing polyphenoloxidases in Galleria larvae after injections of 
bacteria. J. Invert. Path.19: 166-170.

Ratcliffe,N.A. and Gagen,A.P. 1976. Cellular defense reactions of insect hemocytes in vivo: Nodule formation and development in Calleria mellonella and Pieris brassicae larvae. J. of Invert. Path.,28: 373-382.

Ratcliffe,N.A. and Rowley,A.F. 1979. A comparative synopsis of the structure and function of the blood cells of insects and other invertebrates. Devel. and Comp. Immunobiol. 3: 189-243.

Ratner,S. and Vinson,B.S.1983. Phagoctyos is and encapsulation: Cellular immune responses in Arthropoda. Amer. Zool.,23: 185-194.

Rheins, L. and Karp,R. 1982. An inducible humoral factor in the American cockroach, (Periplaneta americana) Precipitin activity that is sensitive to a proteolytic enzyme. J. of Invert. Path. 40: 190-196.

Rizki,M.T. and Rizki,R. 1959. Functional significance of the crystal cells in the larvae of Drosophila melanogaster. Biophys. and Biochem. Cytol.,5(2): 235-240.

Rowley,A.F. and Ratcliffe,N.A. 1979. An ultrastructural and cytochemical study of the interaction between latex particles and the hemocytes of the wax moth, Calleria mellonella in vitro. Ce11 Tissue Res.,199: 127-137.

Rowley,A.F. and Ratcliffe,N.A. 1981. Insects. In; Invertebrate Blood Cells 2. Ratcliffe and Rowley(Eds.)New York: Academic Press,p.421-488.

Salt,G. 1955. Experimental studies in insect parasitism VIII. Host reactions following artificial parasitization. Proc. Roy. Soc. B., 144: 380-400.

Salt,G. 1957. Experimental studies in insect parasitism $X$. The reactions of some endopterygote insects to an alien parasite. Proc. Roy. Soc. B.,147: 167-184. 
Salt,G. 1959. Experimental studies in insect parasitism $X I$. The haemocytic reaction of a catepillar under varied conditions. Proc. Roy. Soc. B., 151: 446-466.

Salt,G. 1963a. Experimental studies in insect parasitism XII. The reactions of six exopterygote insects to an alien parasite. J. Insect Physiol.,9: 647-669.

Salt,G.1963b. The defense reactions of insects to metazoan parasites. Parasitology,53: 527-642.

Salt,G. 1965. Experimental studies in insect parasitism. XIII. The haemocytic reaction of a catepillar to eggs of its habitual parasite. Proc. Roy. Soc. B.,162: 303-318.

Salt,G. 1970a. The Cellular Defence Reactions of Insects. Cambridge University Press.

Salt,G. 1970b. Experimental studies in insect parasitism. $X V$. The means of resistance of a parasitoid larva. Proc. Roy. Soc. Lond. B., 176: 105-114.

Salt,G. 1975. The fate of an internal parasitoid, Nemeritis canescans, in a variety of insects. Trans. R. Ent. Soc. Lond., 127: 141-161.

Schmidt,A.R. and Ratcliffe,N.A. 1977. The encapsulation of foreign tissue implants in Galleria mellonella larvae. J. Insect Physiol.,23: 175-184.

Scott,M.T. 1971a. Recognition of foreignness in invertebrates. 1. Transplantation studies using the American cockroach, (Periplaneta americana). Transplantation, 11(1): 78-86.

Scott,M.T. 1971b. Recognition of foreignness in invertebrates. II. in vitro studies of cockroach phagocytic hemocytes. Immunology,21(2): 817-828. 
Soderhall,K. 1981. Fungal cell wall B-1,3-glucans induce clotting and phenoloxidase attachment to foreign surfaces of crayfish hemocyte lysate. Dev. and Comp. Immun., 5: 565-573.

Soderhall,K. and Unestam,T. 1979. Activation of serum prophenoloxidase in arthropod immunity. The specificity of cell wall glucan activation and activation by purified fungal glycoproteins of crayfish phenoloxidase. Can. J. Microbiol.,25: 406-414.

Stynen,D, Peferoen,M. and Deloof,A. 1982. Proteins with haemagglutinin activity in larvae of the Colorado beetle, Leptinot arsa decem/ineata. J. Insect Physiol., 28(5): 465-470.

Tripp, M.R. 1971. Immunity in invertebrates. In; Aspects of the Biology of Symbiosis. Cheng,T.C.(Ed.),p.275-281.

Vasta,G.R, Sullivan,J.T and Cheng,T.C. and Marchalonis, J.J. and Warr,G.W. 1982. A cell membrane - associated lec$t$ in of the oyster hemocyte. J. of Invert. Path.,40: $367-377$.

Vinson, S.B. 1971. Defense reactions and hemocytic changes in Heliothis viriscens in response to its habitual parasitoid Cardiochiles nicriceps. J. of Invert. Path.,18: 94-100.

Wheeler,R.E. 1963. Studies on the total haemocyte count and haemolymph volume in Periplaneta americana (L.) with special reference to the last moulting cycle. J. Insect Physiol., 9: 223-235.

Whitcomb, R.F., Shapiro, M. and Granados,R. 1974. Insect defense mechanisms against microorganisms and parasitoids. In; The Physiology of Insecta. M. Rockstein(Ed.) New York and London: Academic Press,p.447.

Yeaton,R.W. 1983. Wound responses in insects. Amer. Zool., 23: $195-203$. 
APPENDIX A 
Abbreviations

$\mathrm{D}$

Dn

F

Gh

G

$\mathrm{H}$

I

Ip

Lm

L

M

Me

$\mathrm{N}$

$\mathrm{Nm}$

$\mathrm{Pm}$

$\mathrm{P}$

P1

Rer

$\mathrm{S}, \mathrm{Si}$

$\mathrm{V}$

Cellular debris

Deteriorating nucleus

Fibrous structure

Granular hemocyte

Golgi complex

Hemocyte

Electron-dense inclusion

Implant

Lysed cellular material

Longitudinal section

Mitochondria

Membrane

Nucleus

Nuclear membrane

Plasma membrane

Protoplasmic extension

Plasmatocyte

Rough endoplasmic reticulum

structured inclusion

Vacuole 
APPENDIX B 
MICROGRAPHS 
Figures 1-4. TEM of hemocytes from non-infected adult $P$. americana: Fig.1, Plasmatocyte. Figs.2-4, Granular hemocytes... The presence of varying numbers of electron dense inclusions (I) in the cytoplasm of granular hemocytes distinguishe's, these cells from plasmatocytes. $N$, nucleus; $V$, vacuoles; RER, rough endoplasmic reticulum; $M$, mitochondria; G, Golgi complex; P, protoplasmic extensions. 

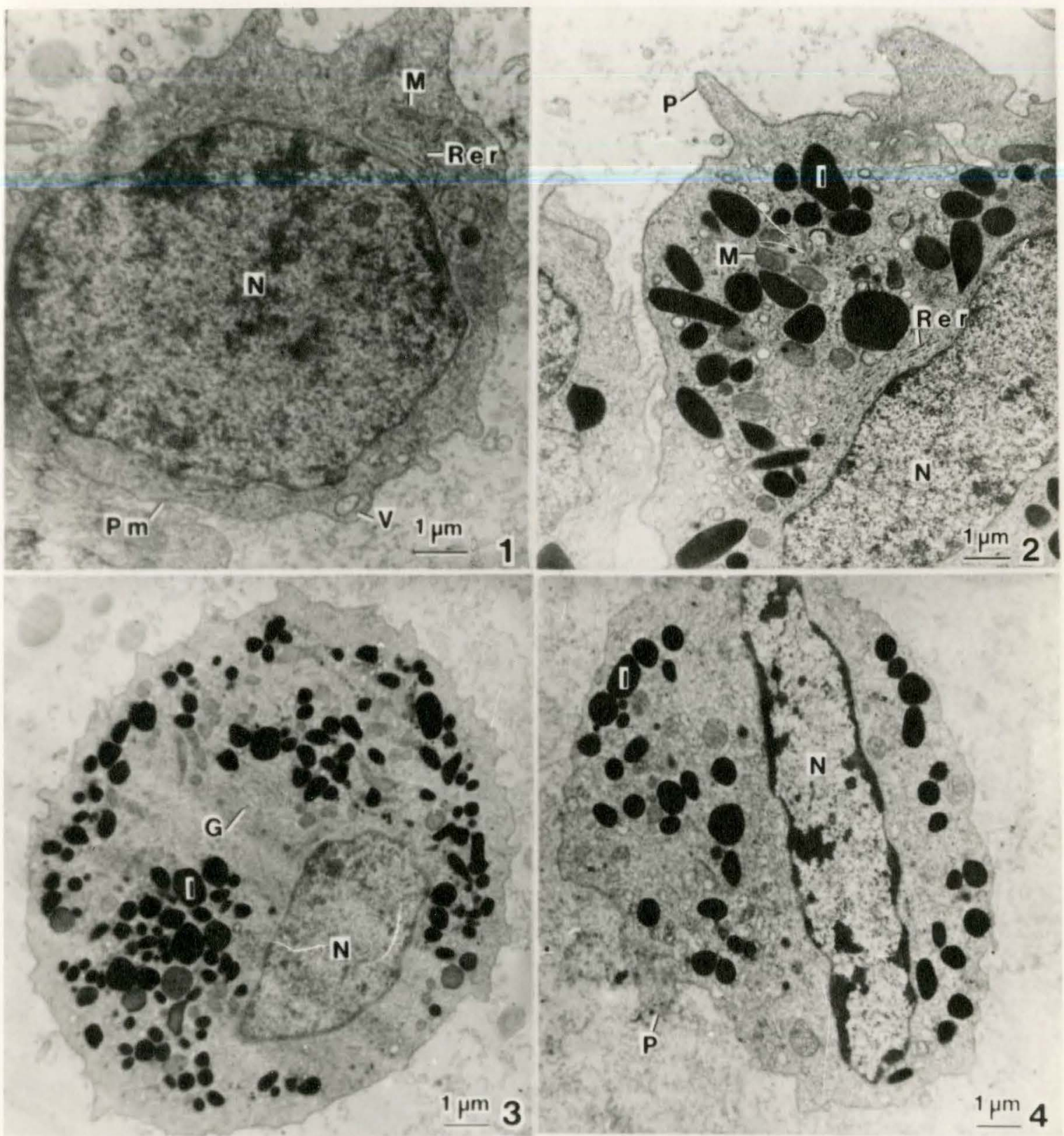
Figs.5 ard 6. Granular hemocytes showing varying numbers of electron dense cytoplasmic inclusions, (I), moderately sized vacuoles, (V), and an occasional inclusion with a more structured shape, (S). N, nucleus.

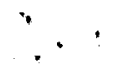



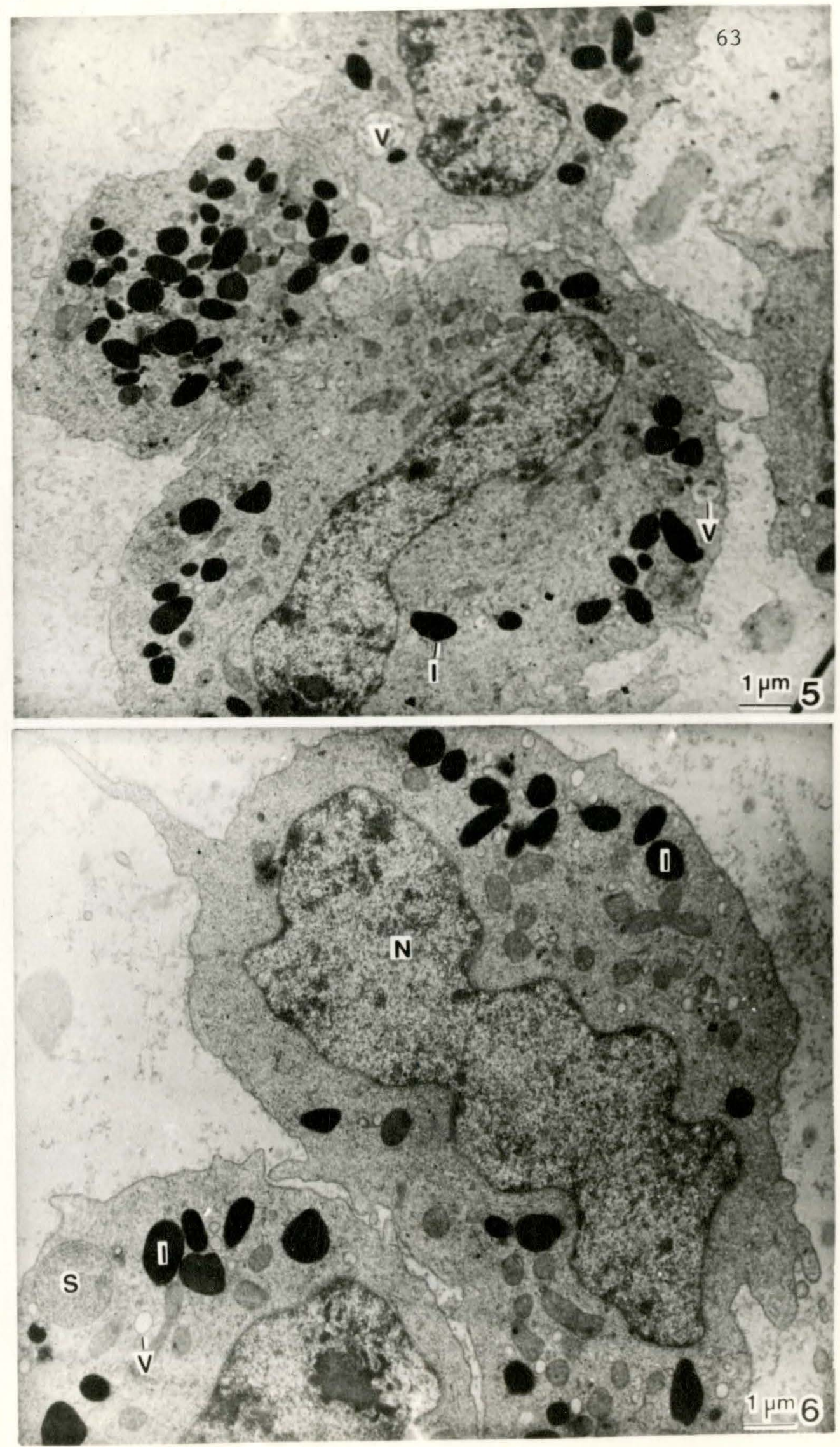
Fig.7. SEM of a section of an unaltered nerve cord dissected from $P$. americana. Mag. 103x.

Figs. 8 and 9 . SEM of a section of unaltered nerve cord from donor Periplaneta 1 hour after implantation into a $P$. americana recipient. Note hemocytic responses at only those areas where the surface had been damaged. Unaltered surfaces remain free of hemocytes. (Mag.,Fig.8,139x; Fig. 9, 278x) 

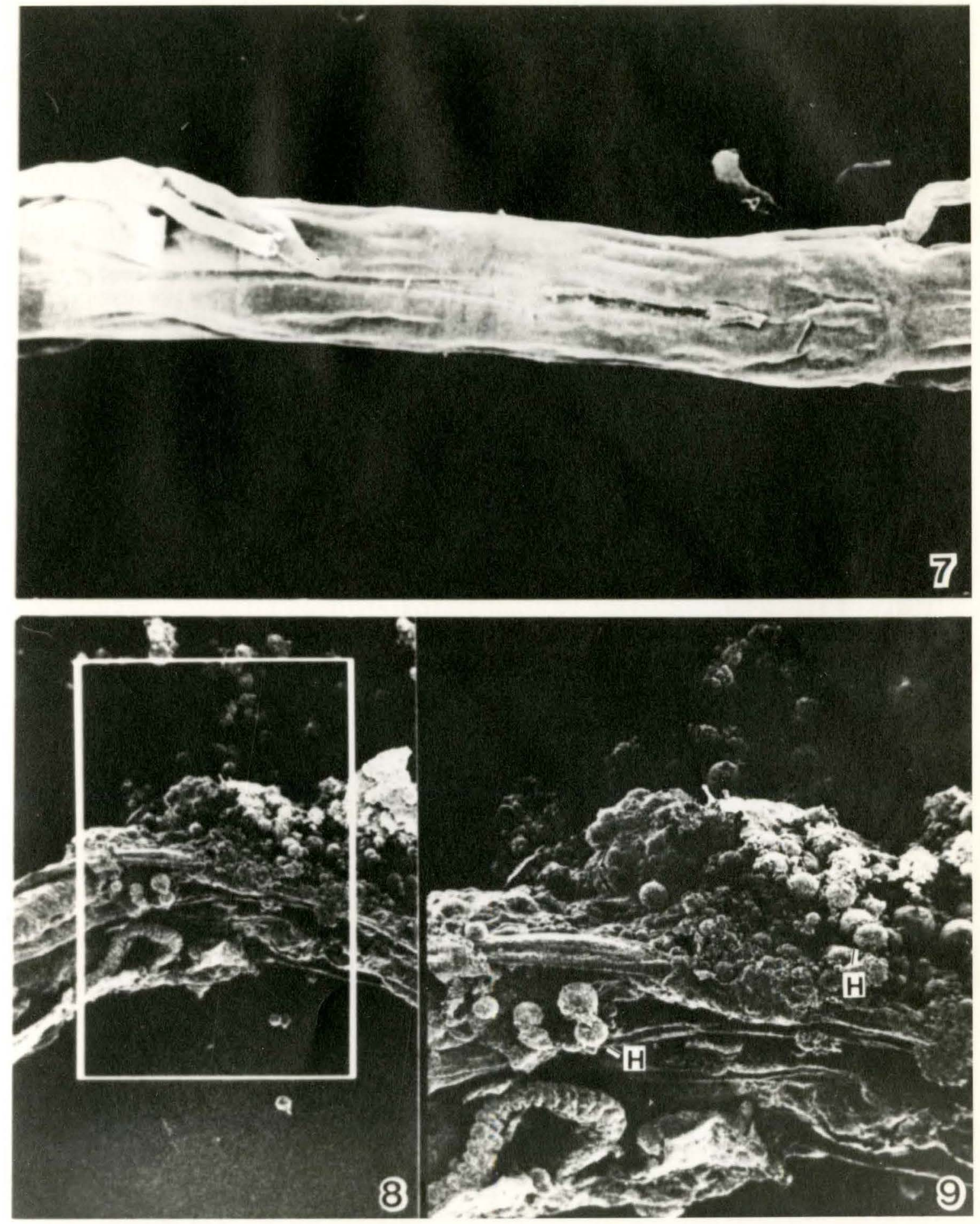
Figs. 10 and 11. Micrographs showing the early lysis of granular hemocytes (GH) at the surface of the implant at 5 minutes. I, Cytoplasmic inclusions, $M$, mitochondria, and other components of the cytoplasm. Ip, surface of implant; Pm, plasma.membrane. 

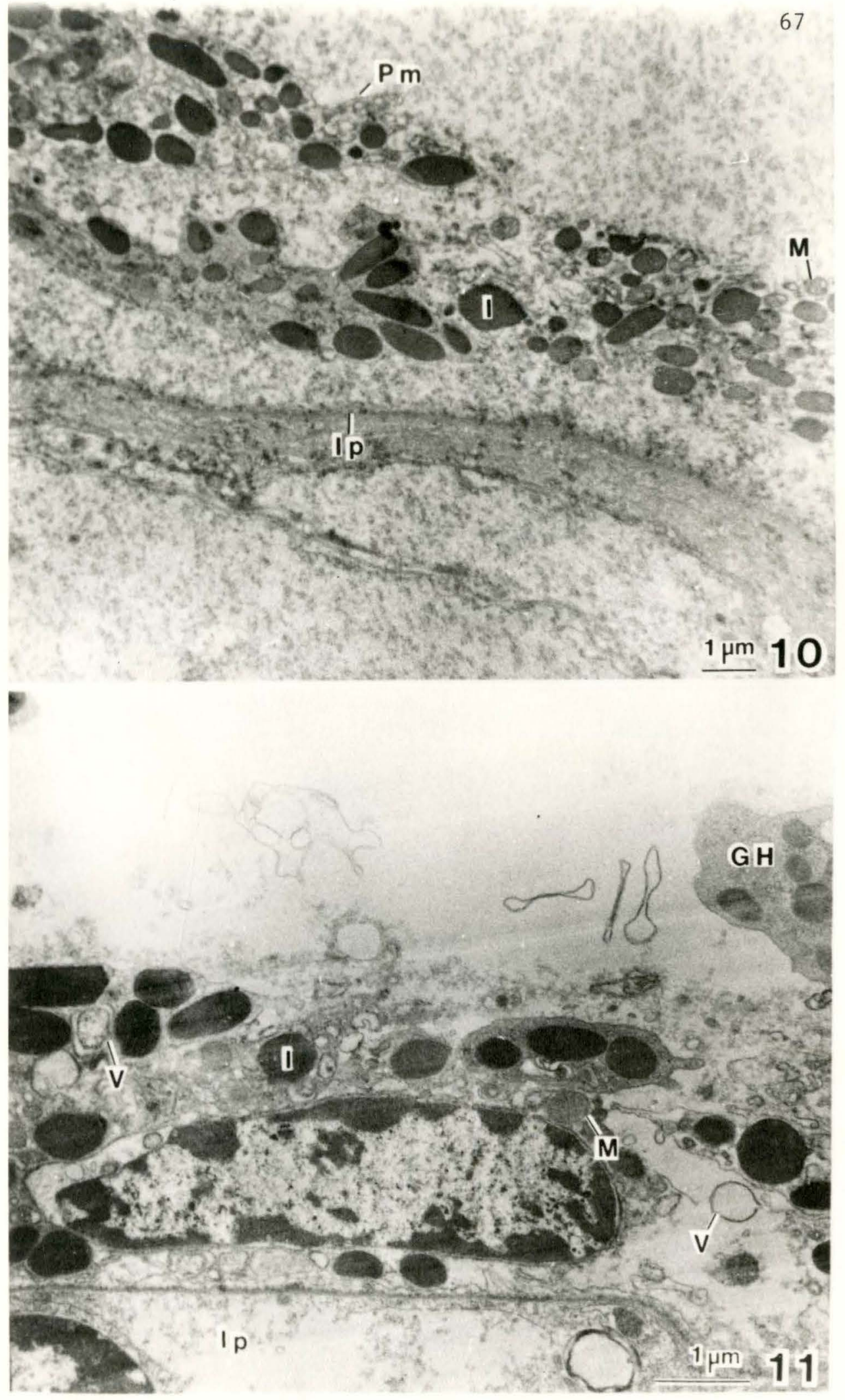
Fig.12. Lysed cellular material deposited along the implant surface(Ip), 10 minutes after implantation. I, electron dense inclusions; $M$, mitochondria.

Fig.13. Lysed cellular material 30 minutes after implantation. Note the degree of deterioration of the cellular debris which has taken place from the 10 minute period in the previous photograph. 


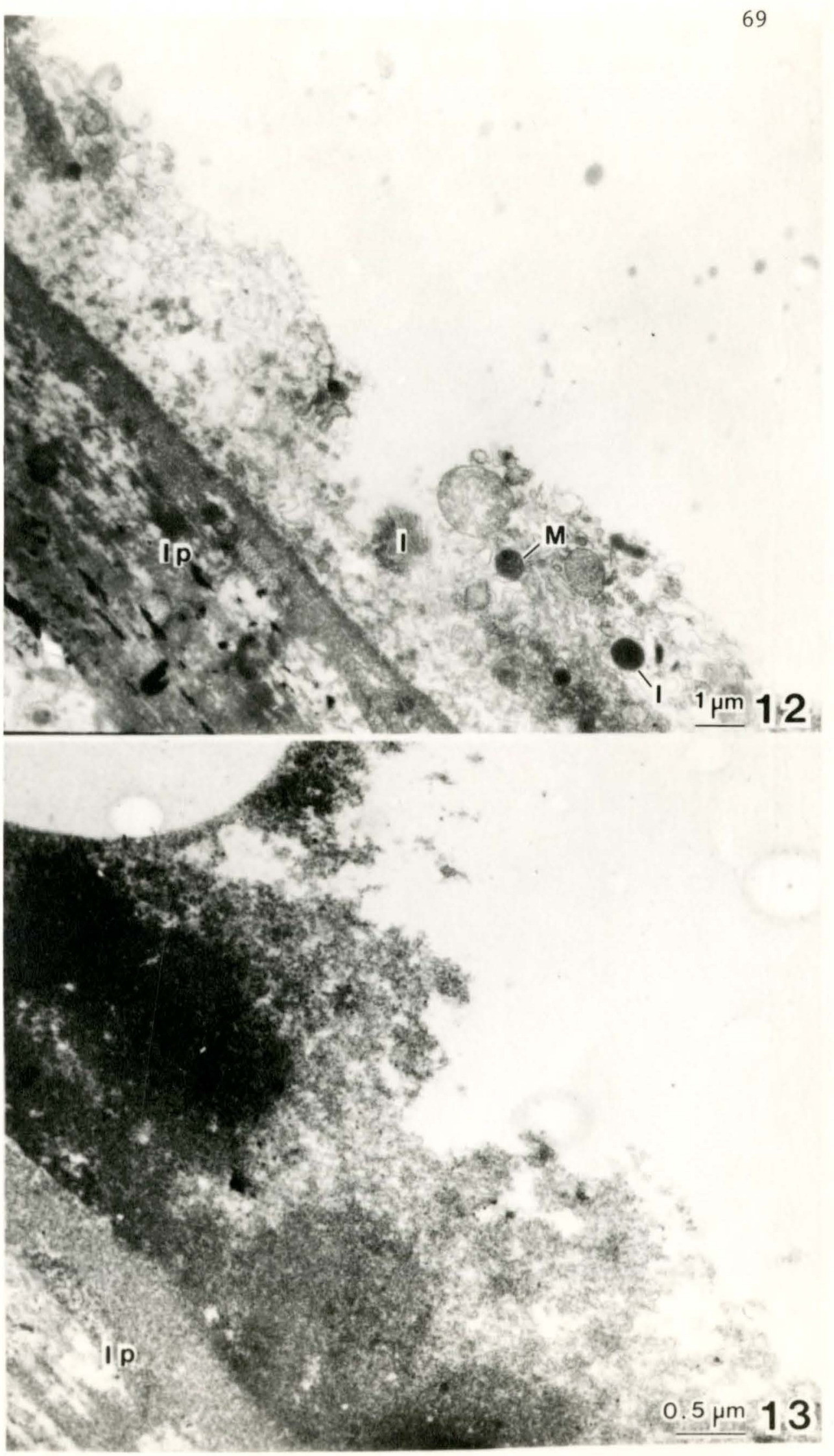


Fig.14: Additional accumulation of granular hemocytes 15 minutes after implantation of the nerve cord, (Ip). Cellular organelles of these cells are still identifiable, Dn, deteriorating nucleus; $I$, inclusions; $M$, mitochondria; Pm, plasma membrane; $\mathrm{Nm}$, nuclear membrane.

Fig.15. Lysis of peripheral cells at 15 minutes is evident some distance from the surface of the implant (Ip). Two intact granular hemocytes can be seen exhibiting large vacuoles (V). Lm, lysed celular material; I, inclusion. 

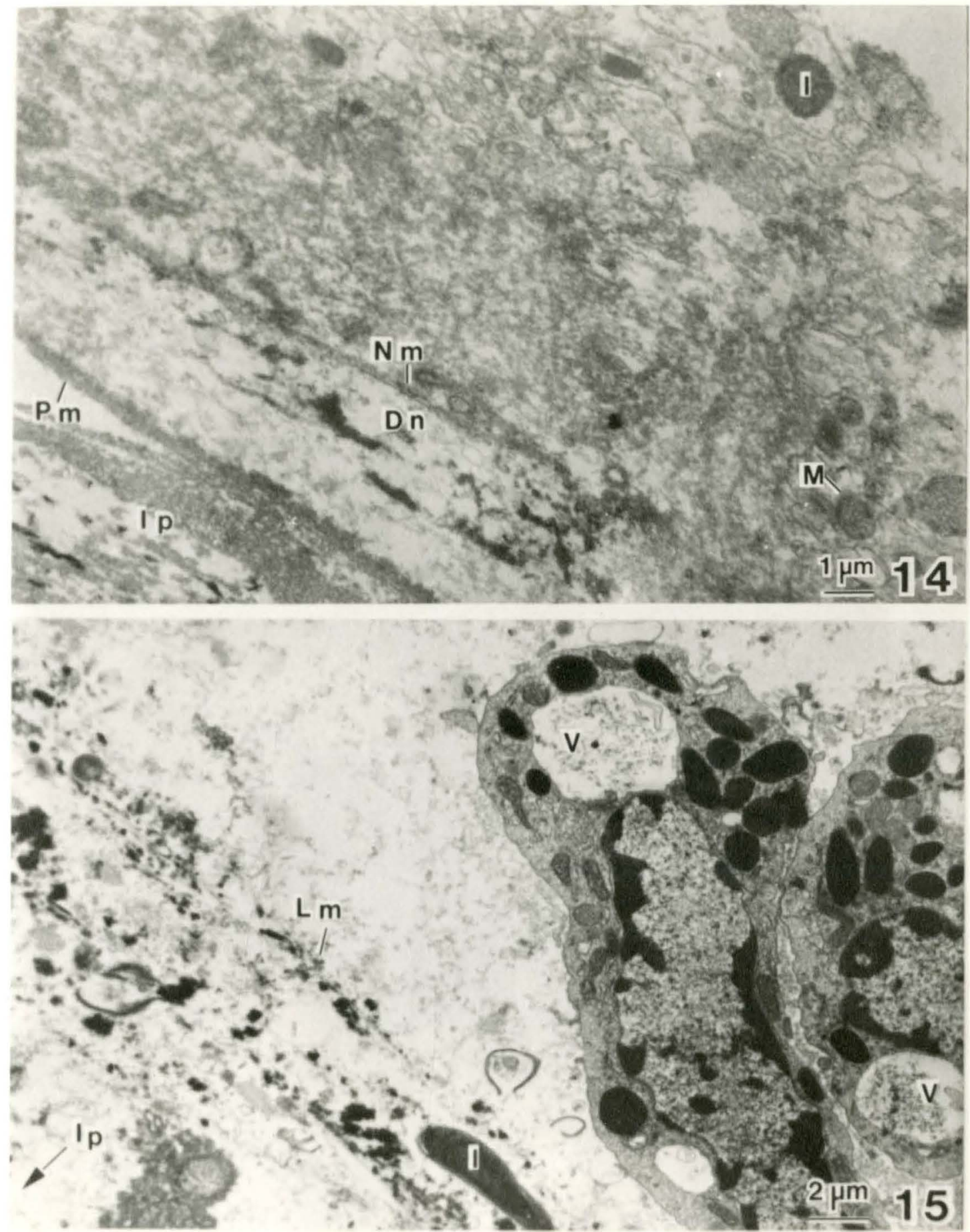
Fig.16. Enlargement of Fig.15 showing intact granular hemocytes peripheral to the implant in the vicinity of lysed cellular material, ( $\mathrm{Lm})$. The implant is located to the lower left of these cells. Phagocytosis of cellualr debris by these cells is indicated by large vacuoles, (V), containing debris similar to that seen extracellularly. 


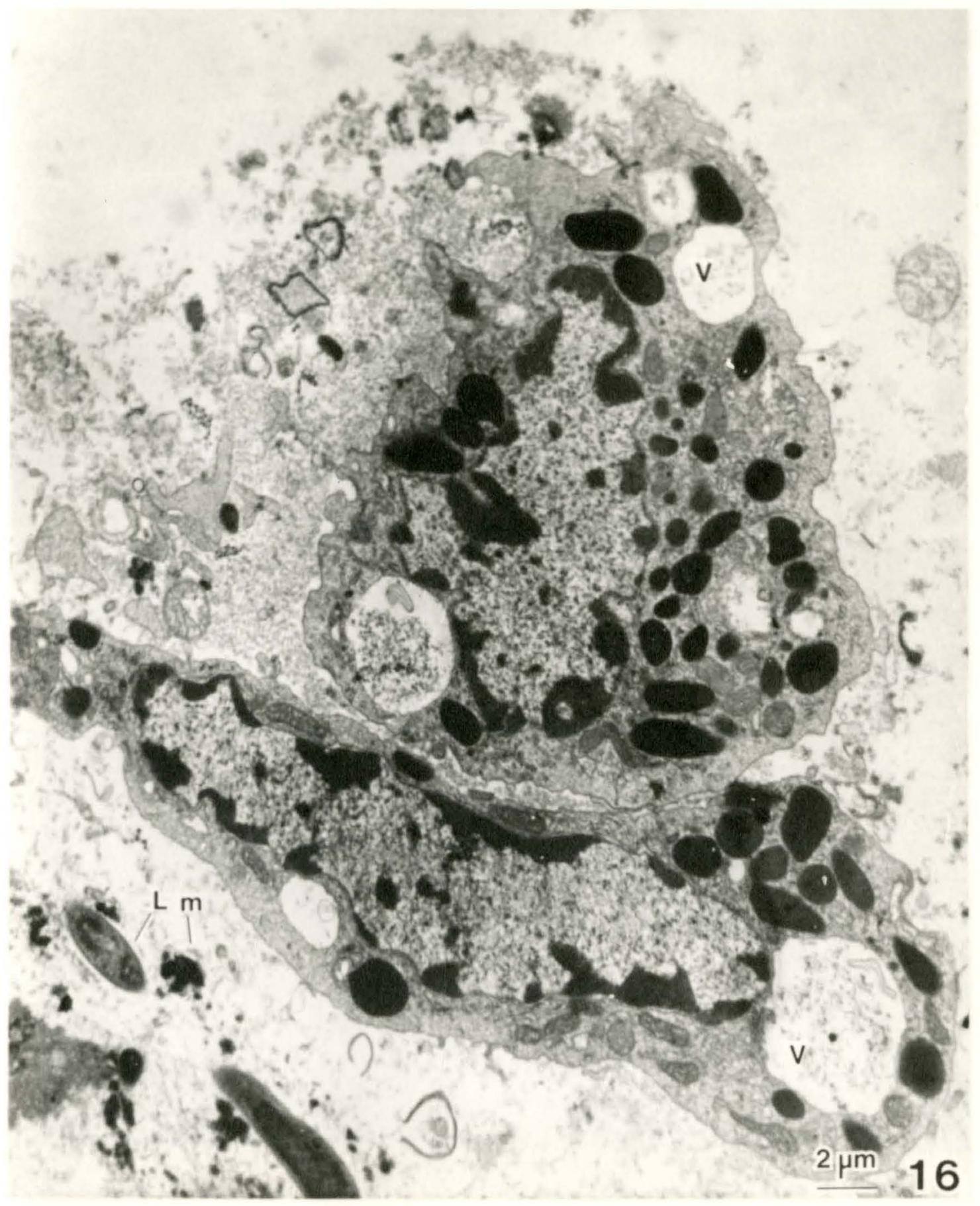


Fig.17. Aggregations of hemocytes some distance from the implant 15 minutes after implantation. Although not shown the implant is located in the lower left corner. Lys is of some peripheral cells has occurred as evidenced by the deterioration of the plasma membrane $(\mathrm{Pm})$, and the presence of extracellular electron dense, cytoplasmic inclusions (I). P1, plasmatocyte. 


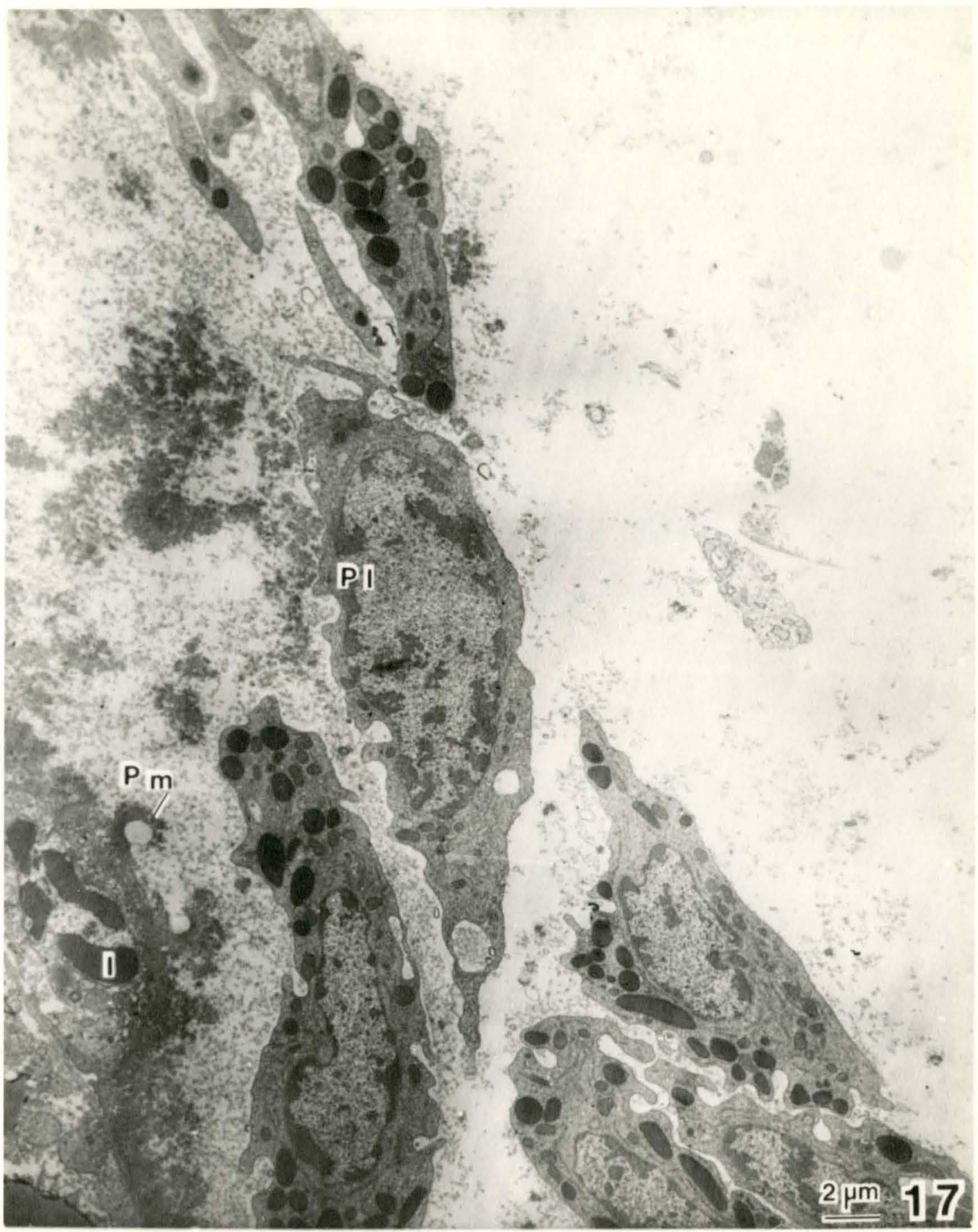


Figs.18 and 19. Aggregations of intact granular hemocytes at 15 minutes. Cells exhibit extremely pleomorphic shapes. The implant is located in the region of the lower left corner of both micrographs. Note the cylinder shaped inclusions (Sil, intra- and extracellularly in the lower micrograph. Lm, lysed cellular material; $\mathrm{N}$, nucleus. 

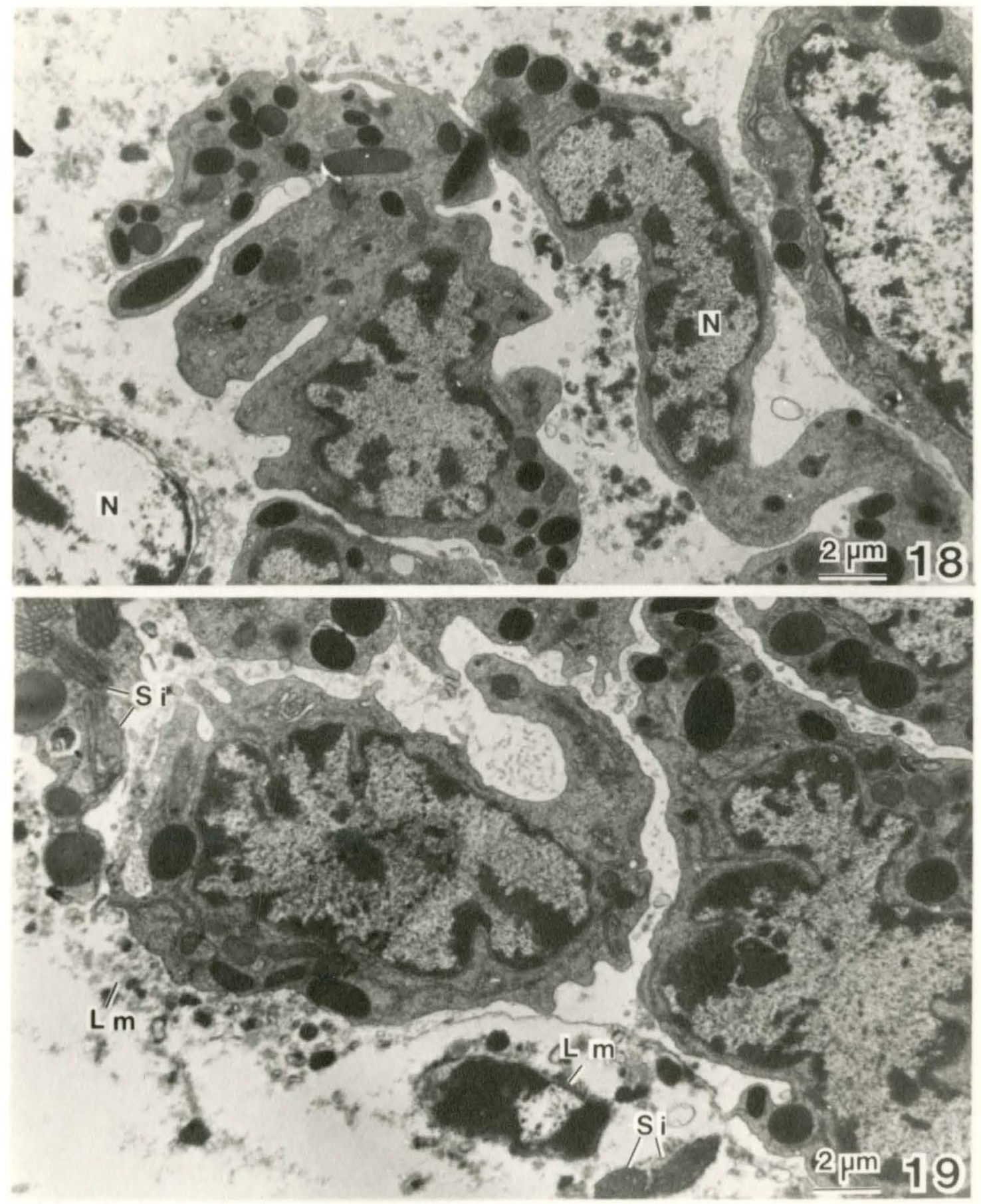
Fig.20. Lysis of hemocytes at 30 minutes. Note the numerous structured inclusions, ( $\mathrm{Si}$ ), and a fibrous structure (F). Lysis of the plasma membranes, (Pm), is apparent although no contact with the implant is observed. N, nucleus; Nm, nuclear membrane. (Implant is out of view at the lower left.) 


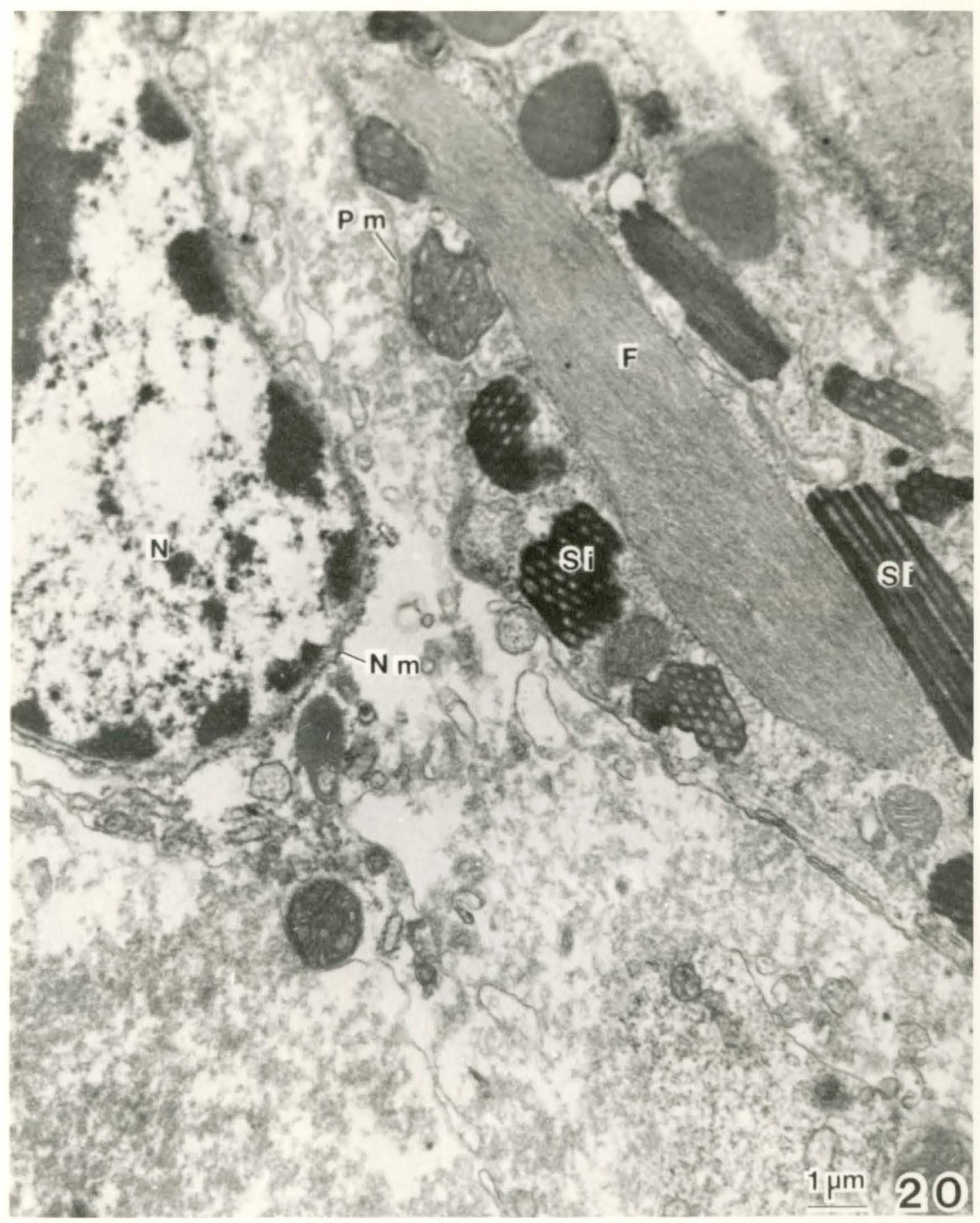


Figs. 21 and 22. Granular hemocytes at 30 minutes showing electron dense inclusions (I), and structured or honeycombed inclusions ( $\mathrm{Si}$ ), in the cytoplasm. In longitudinal sections (L) the honey-combed inclusions appear to be comprised of cylindrical tubules. In cross sections these tubules are seen with single (S) and double (D) membranes. Me, outer membrane surrounding the structured inclusions. 


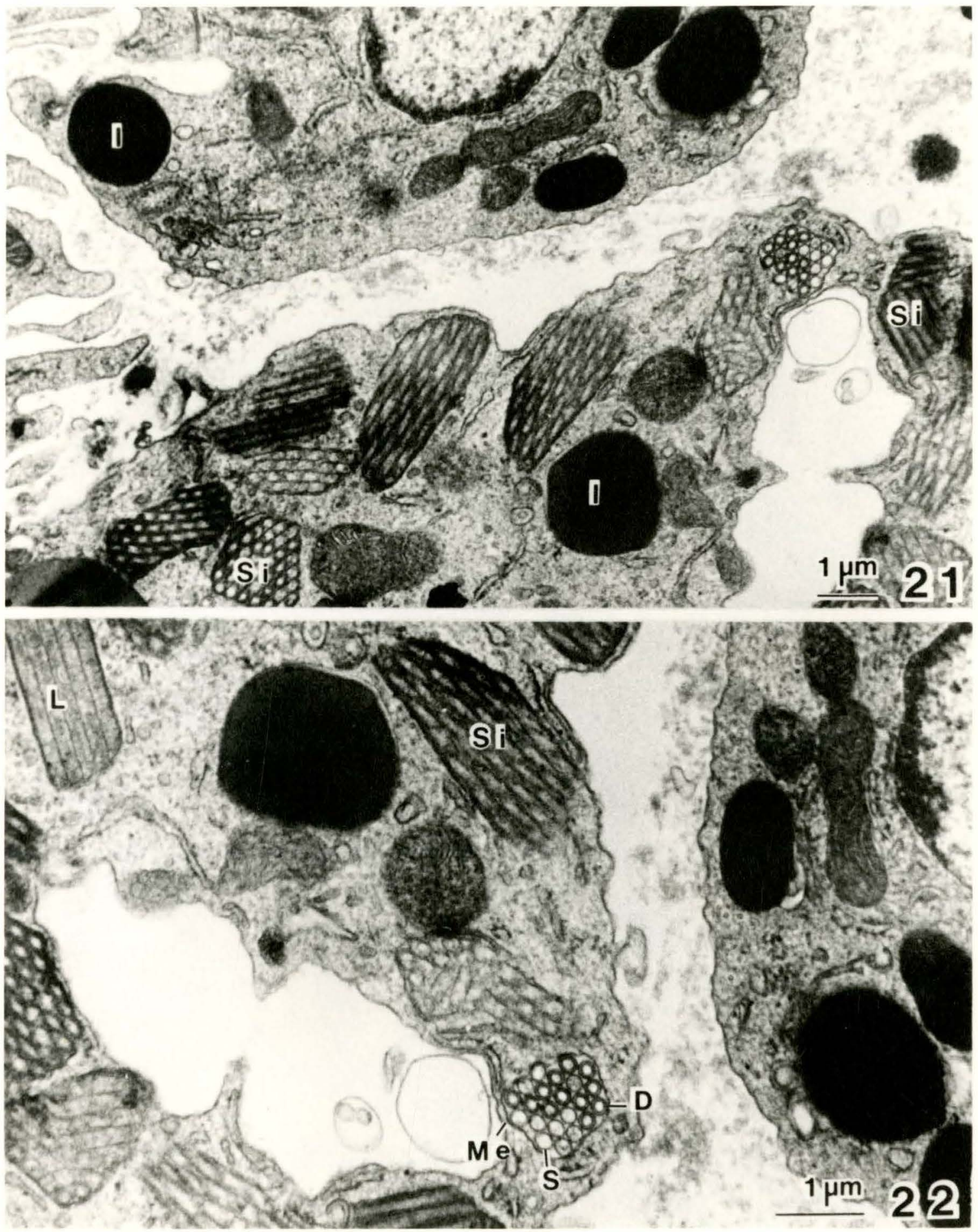




\section{2}

Fig.23. Lysis of cells at 30 minutes. V, large vacuoles; Si, deteriorating structured inclusions. A large intact granular hemocyte is observed peripheral to this activity. 


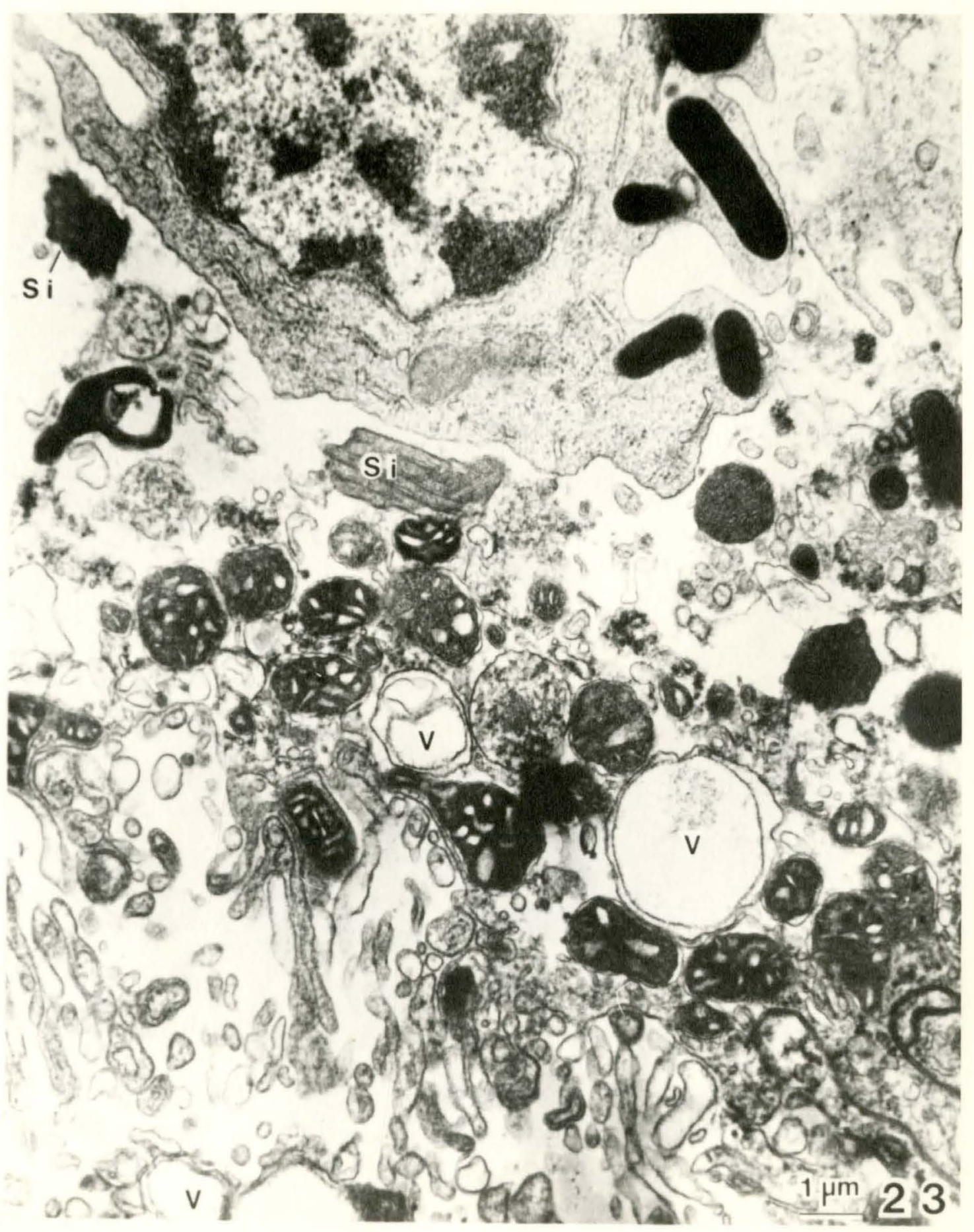


Fig.24. The layering of hemocytes on the surface of the implant (Ip) at 45 minutes. D, thin layer of cellular debris; $I$, electron dense inclusions; $\mathrm{N}$, nuclei of hemocytes; $\mathrm{Pm}$, plasma membranes; $V$, vacuoles. 


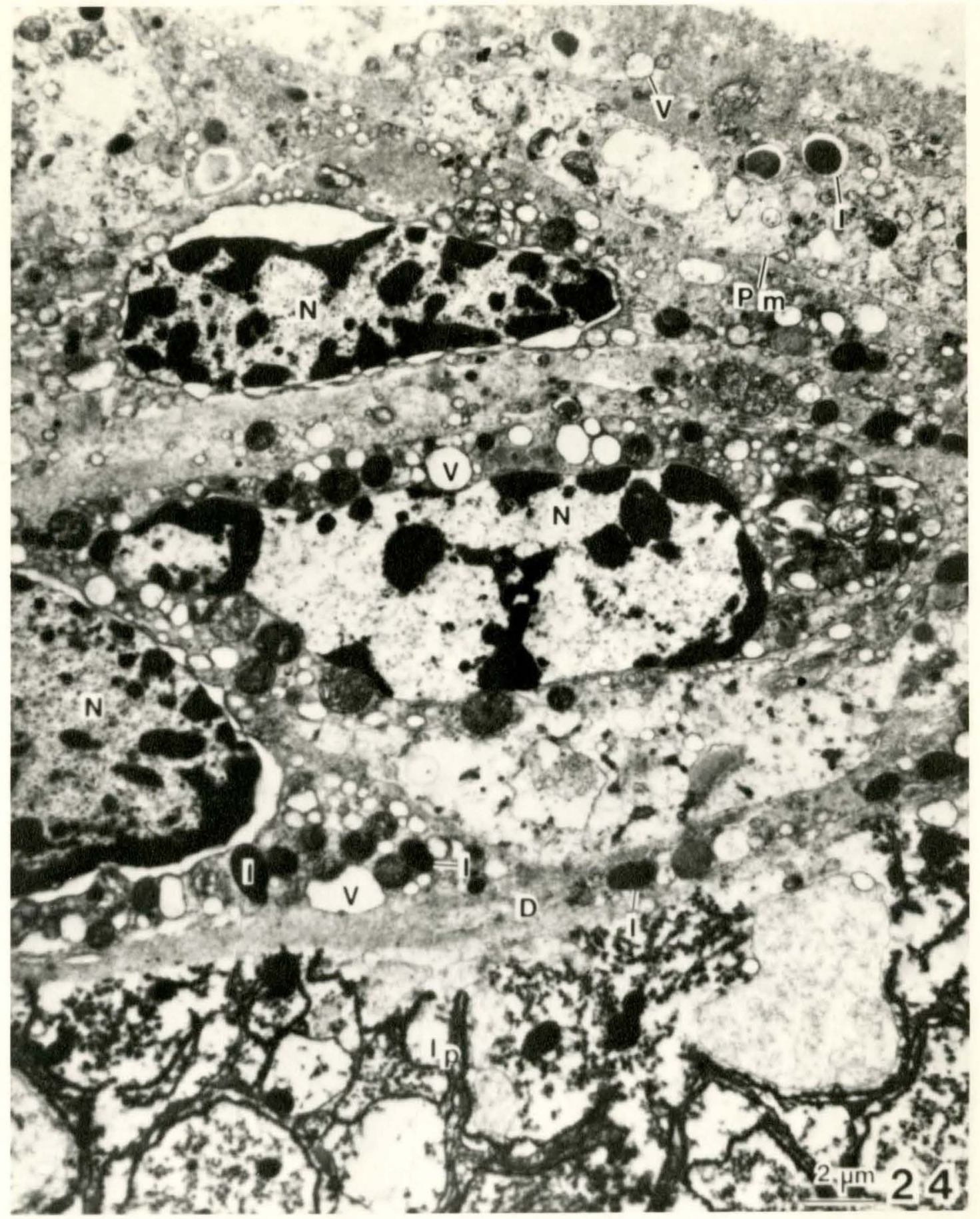


Fig.25. Beginning stages of layering of intact cells against the first layer of cellular debris 45 minutes after implantation. Pictured are granular hemocytes surrounding a plasmatocyte (P1). P, protoplasmic extensions; Pm, plasma membrane; $V$, vacuoles.

Fig.26. Developing capsule at 45 minutes. Cells have become highly vacuolated (V); Pm, plasma membrane; $M$, mitochondria; I, electron dense inclusions; D, extracellular debris. This activity is peripheral to the initial layers of hemocytes forming at the surface of the implant. 

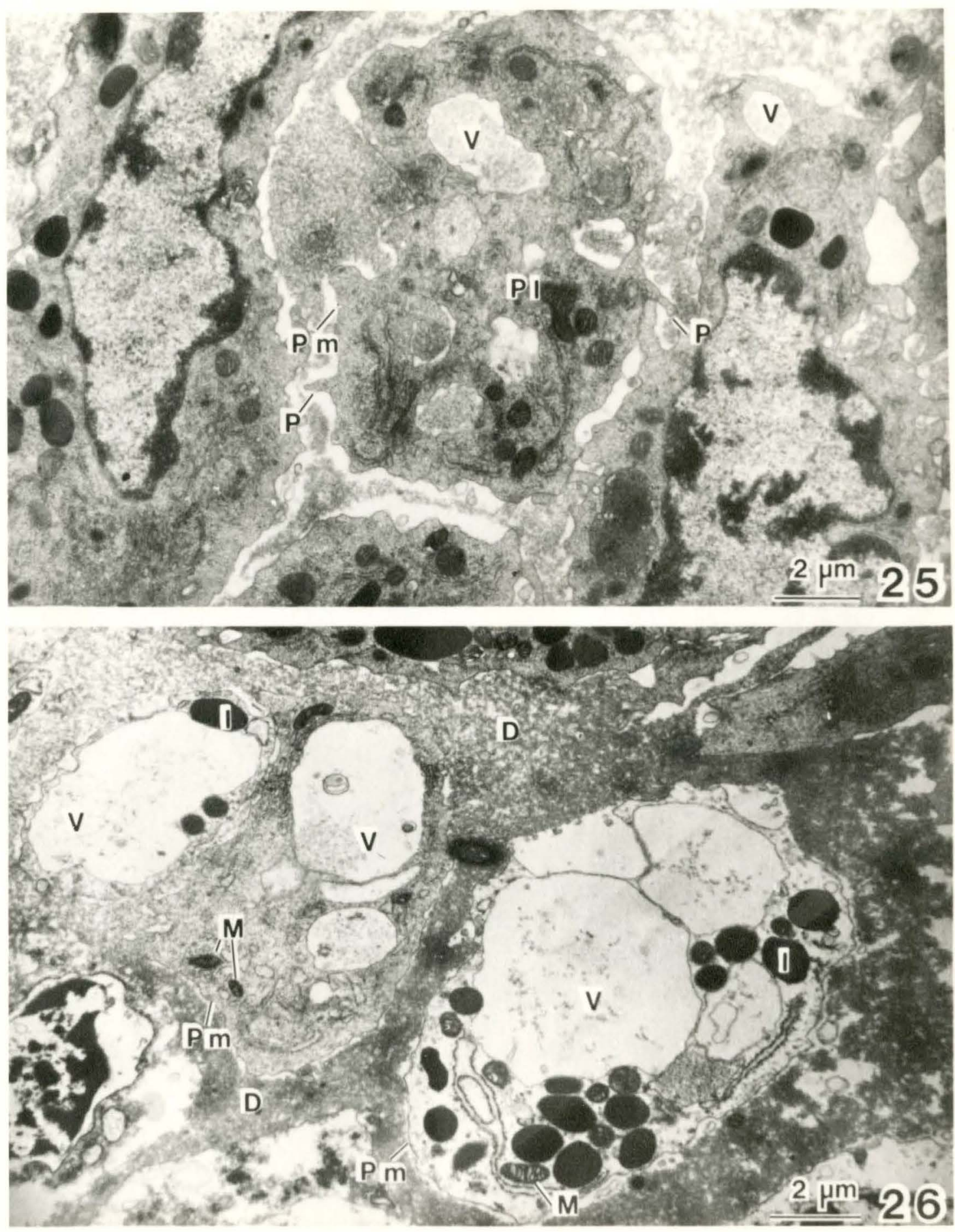
Fig.27. Capsule development at 1 hour. About 6 cell layers are observed against the implant (Ip), and the initial layer of cellular debris (D); $V$, vacuoles; $N$, elongated nuclei; I, electron dense inclusions. 


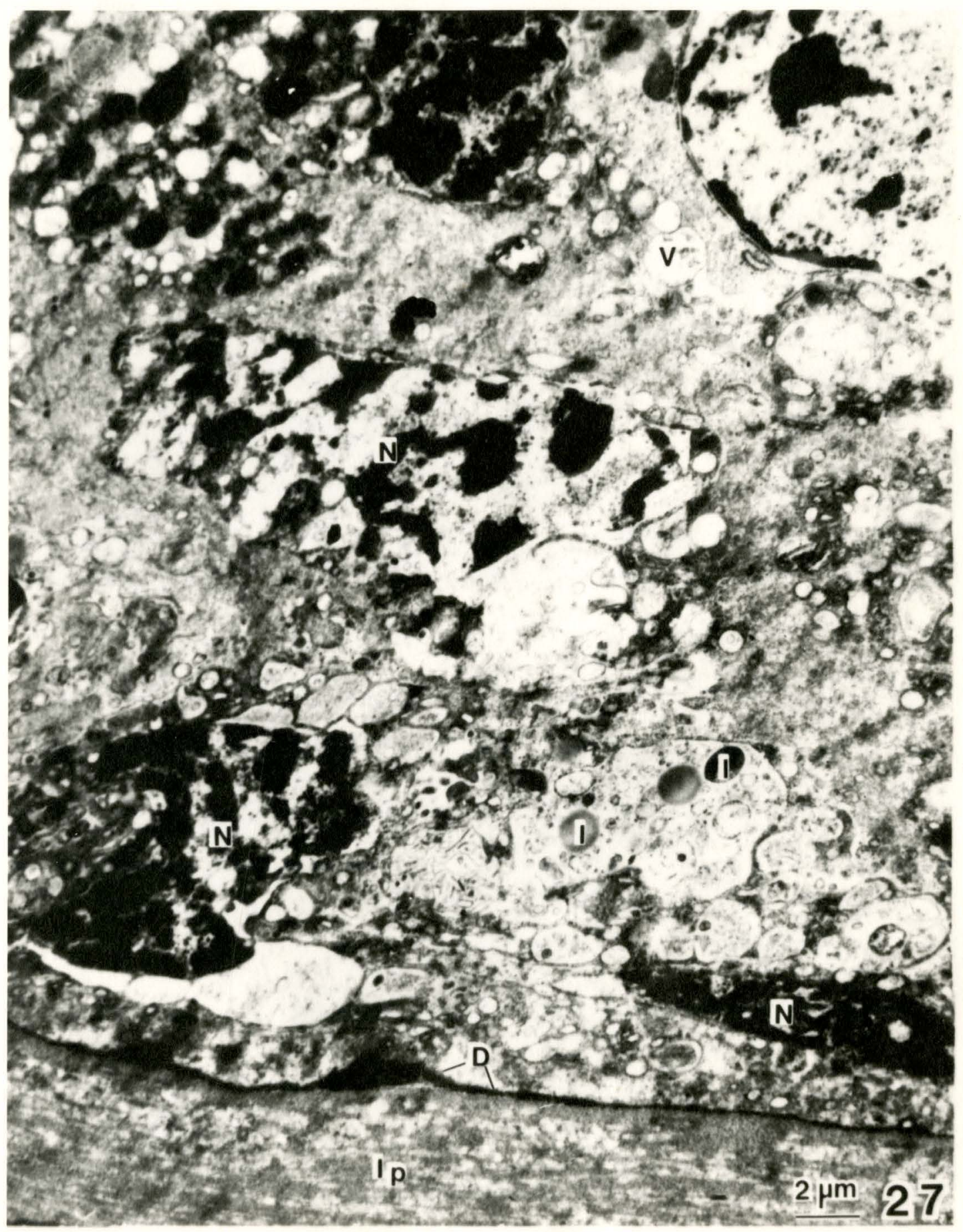


Fig.28. Capsule development at 1 hour. Hemocytes to the left are closest to the surface of the implant and are more necrotic than those cells to the right. $V$, numerous small vacuoles; $\mathrm{N}$, nuclei; Pm, plasma membrane; I, inclusions.

Fig.29. Granular hemocytes peripheral to the capsule development at 1 hour. These cells are more typical of freely circulating hemocytes and exhibit small protoplasmic extensions (P) of the plasma membrane (Pm); I, inclusions. 

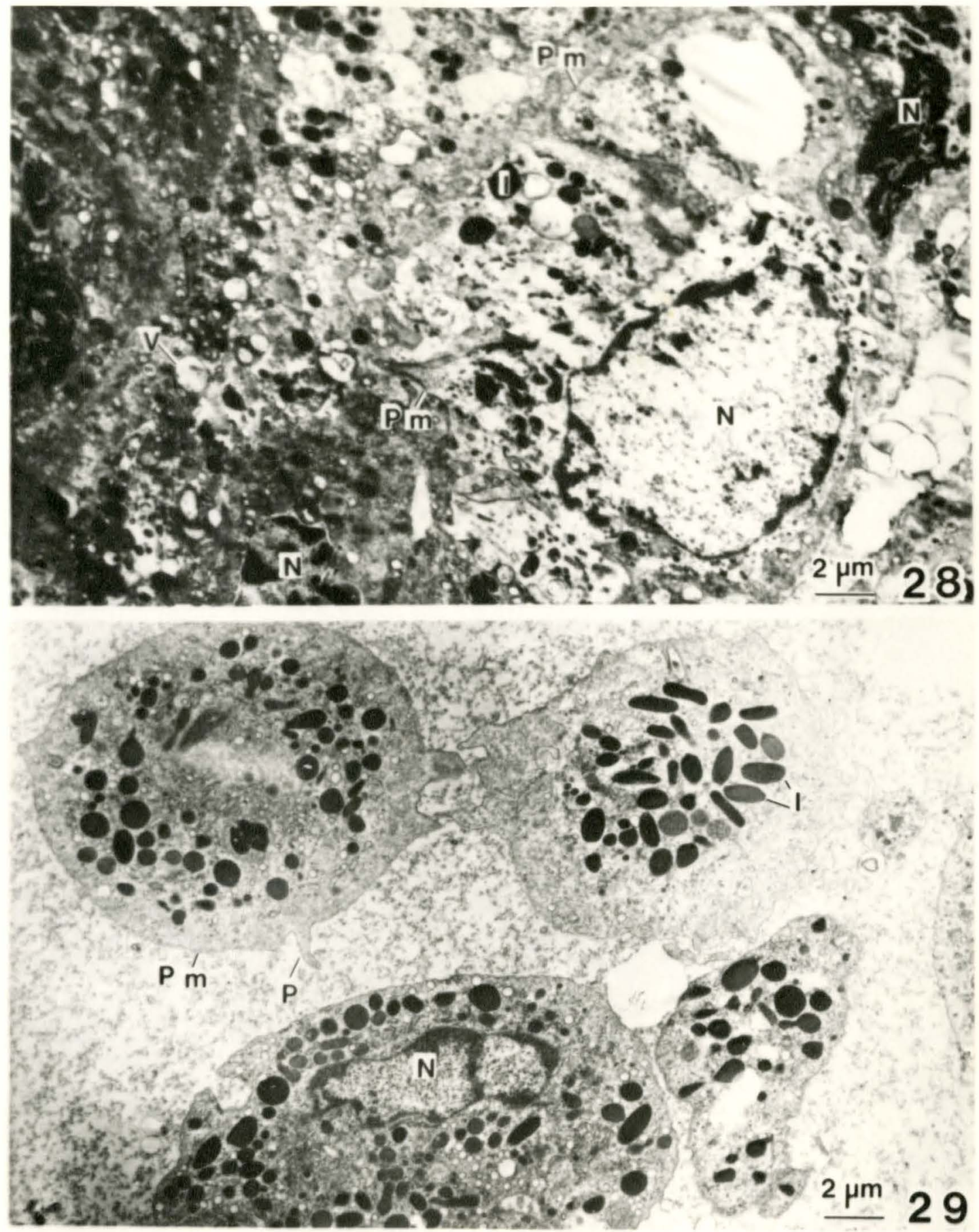
Fig.30. Capsule development at 6 hours. The implant which is not in view is to the lower left. Those cells closest to the implant seem to have formed one continuous mass of material and contain nuclei (N) which are extremely elongated, V, vacuoles; M, mitochondria. Cells exhibit no dense cytoplasmic inclusions. Regions peripheral to this, (arrows), exhibit cells of a more rounder shape, $N$, large pleomorphic nuclei; I, inclusions; Pm, plasma membrane. 


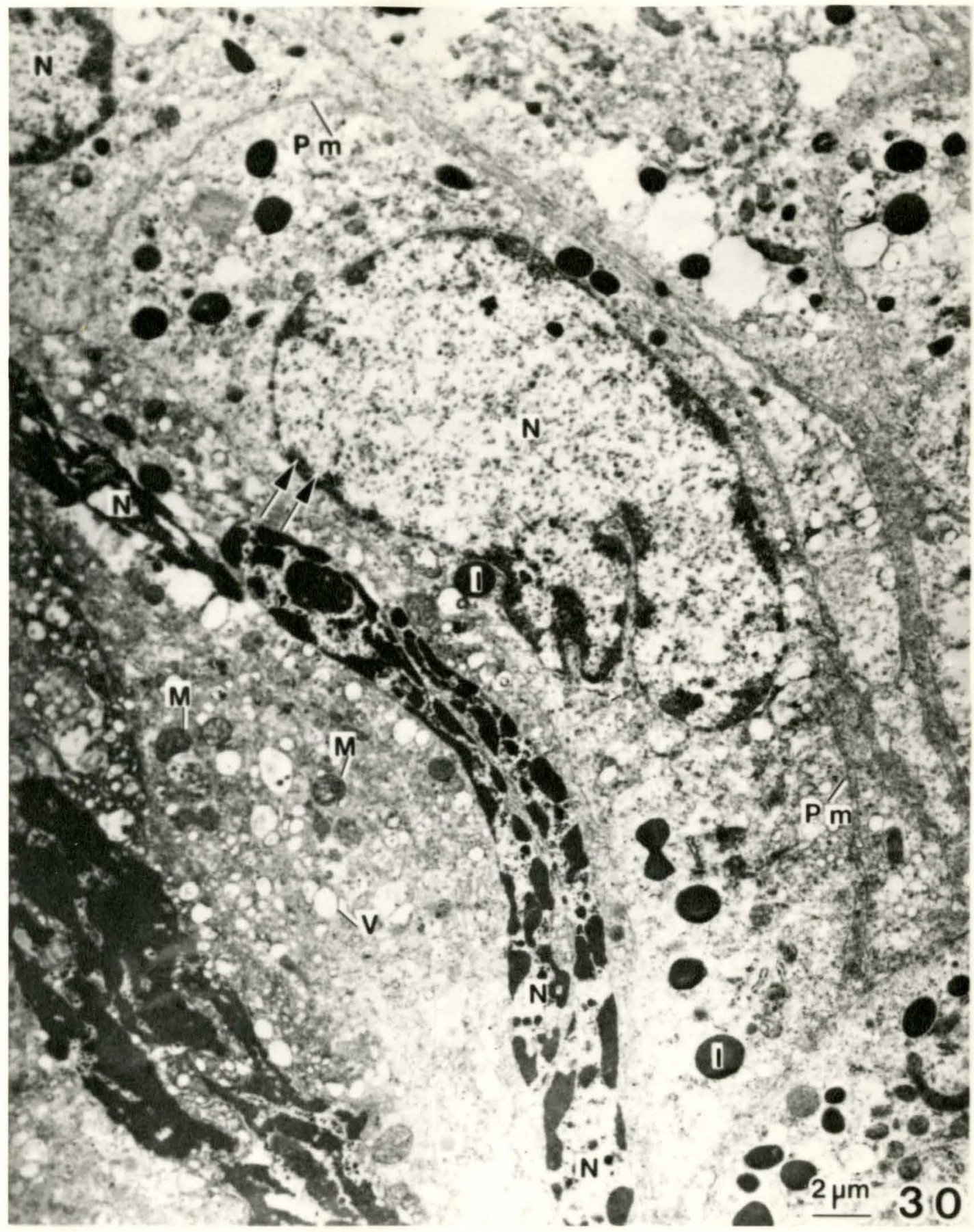


Fig.31. Cells involved in capsule development at the 6 hour stage exhibiting extremely numerous protoplasmic extensions (P); The plasma membranes (Pm) are difficult to distinguish because of interlocking protoplasmic extensions of differing ce11s. V, vacuoles.

Fig.32. Granular hemocytes peripheral to capsule development 6 hours after implantation. Cells are large and morphologically similar to those freely circulating hemocytes. 


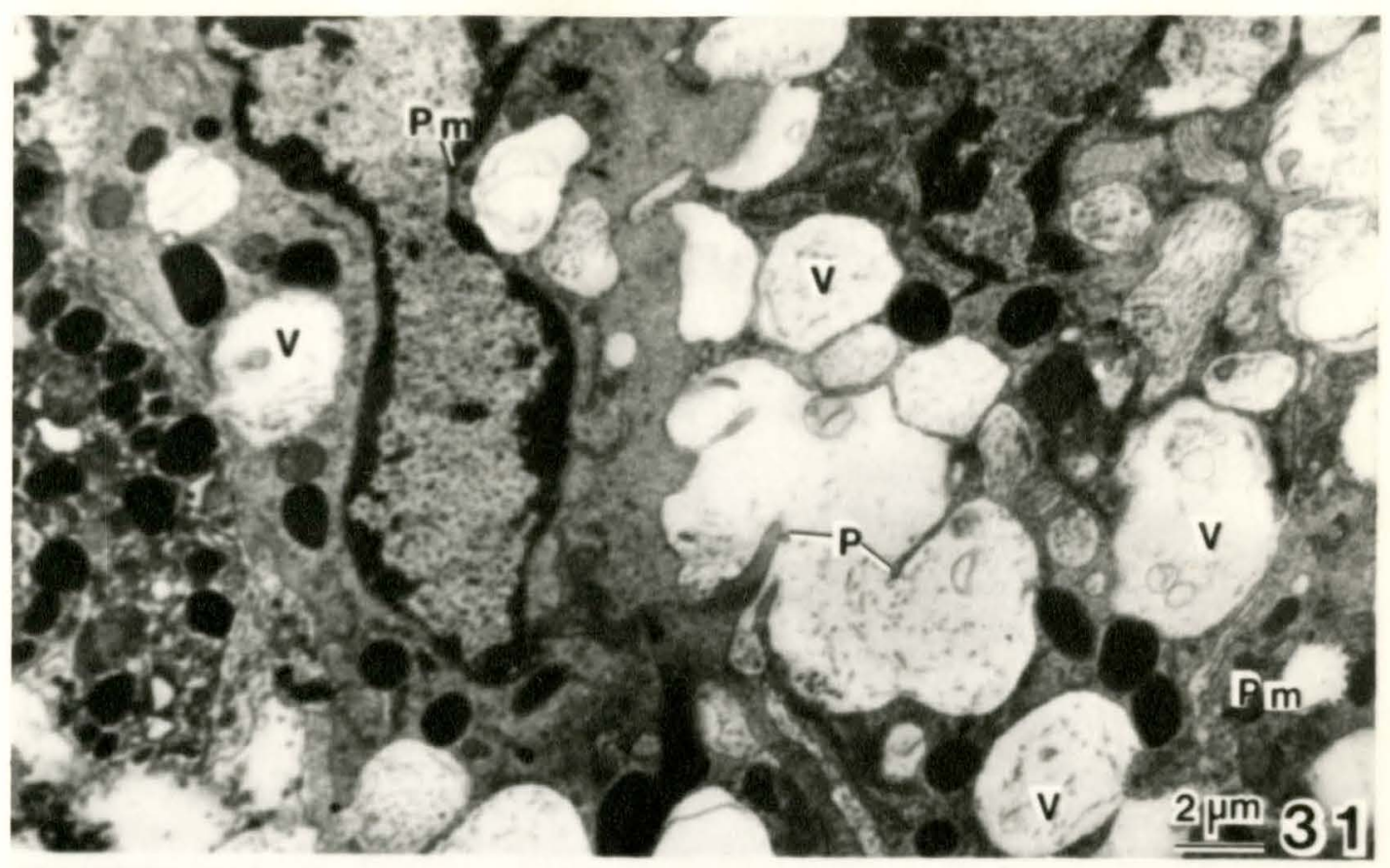

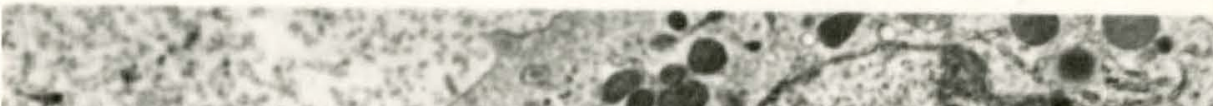

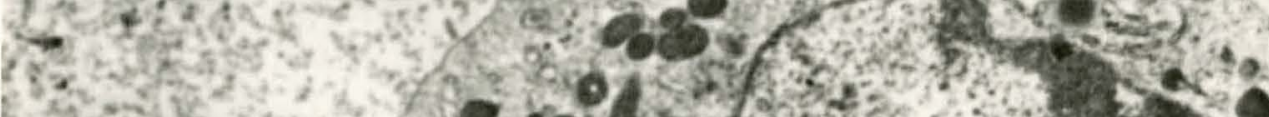

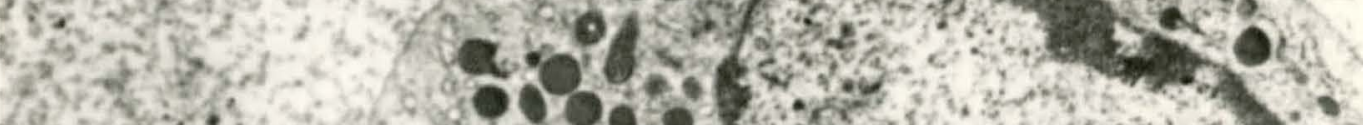

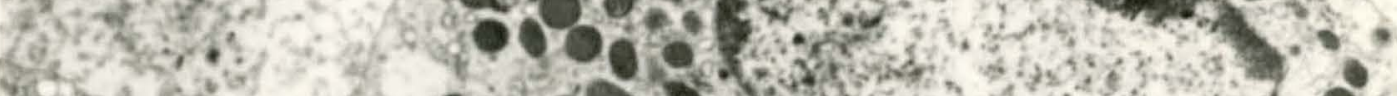

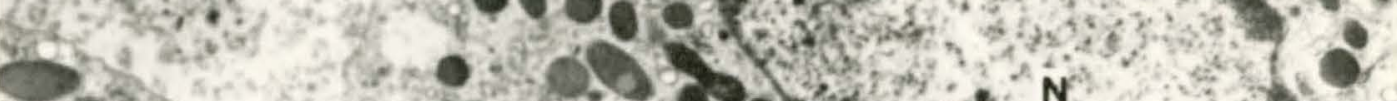
3.

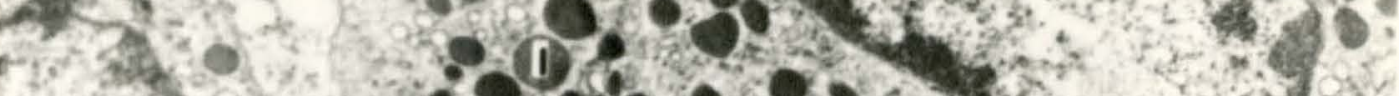

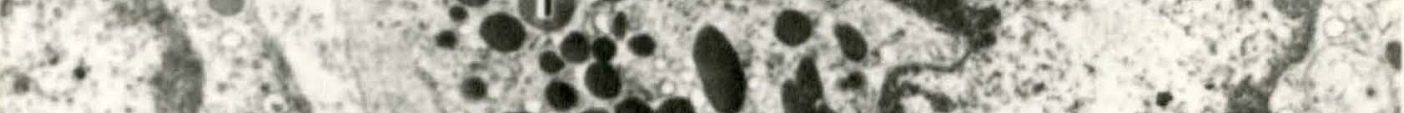
2.5.

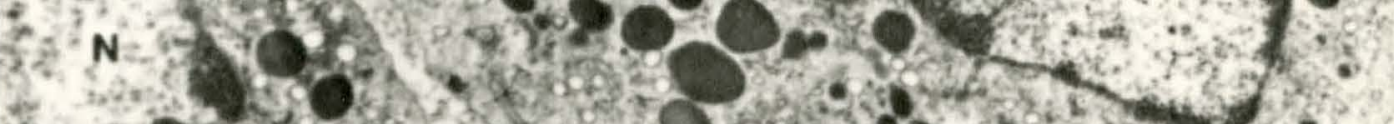

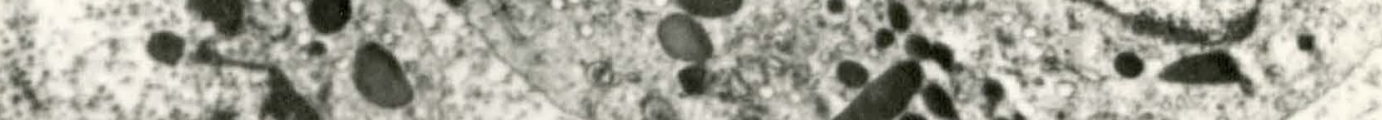

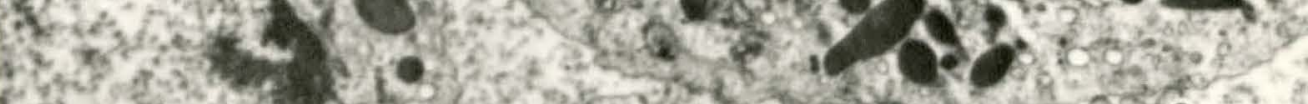

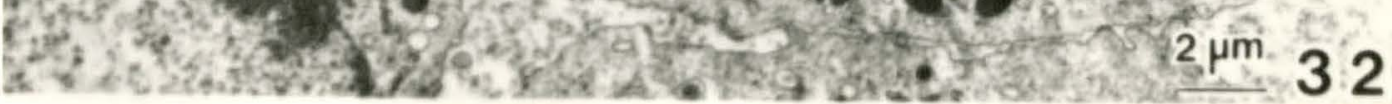


Fig.33. 12. hours after implantation shows increased numbers of hemocytes in capsule development. The implant, although not in view, appears at the bottom. Those more peripheral cells exhibit nuclei (N) which are much less flattened. At least 18 cellular layers are evident at this time period. $I$, electron dense inclusions; $M$, mitochondria; Pm, plasma membranes; D, cellular debris. 


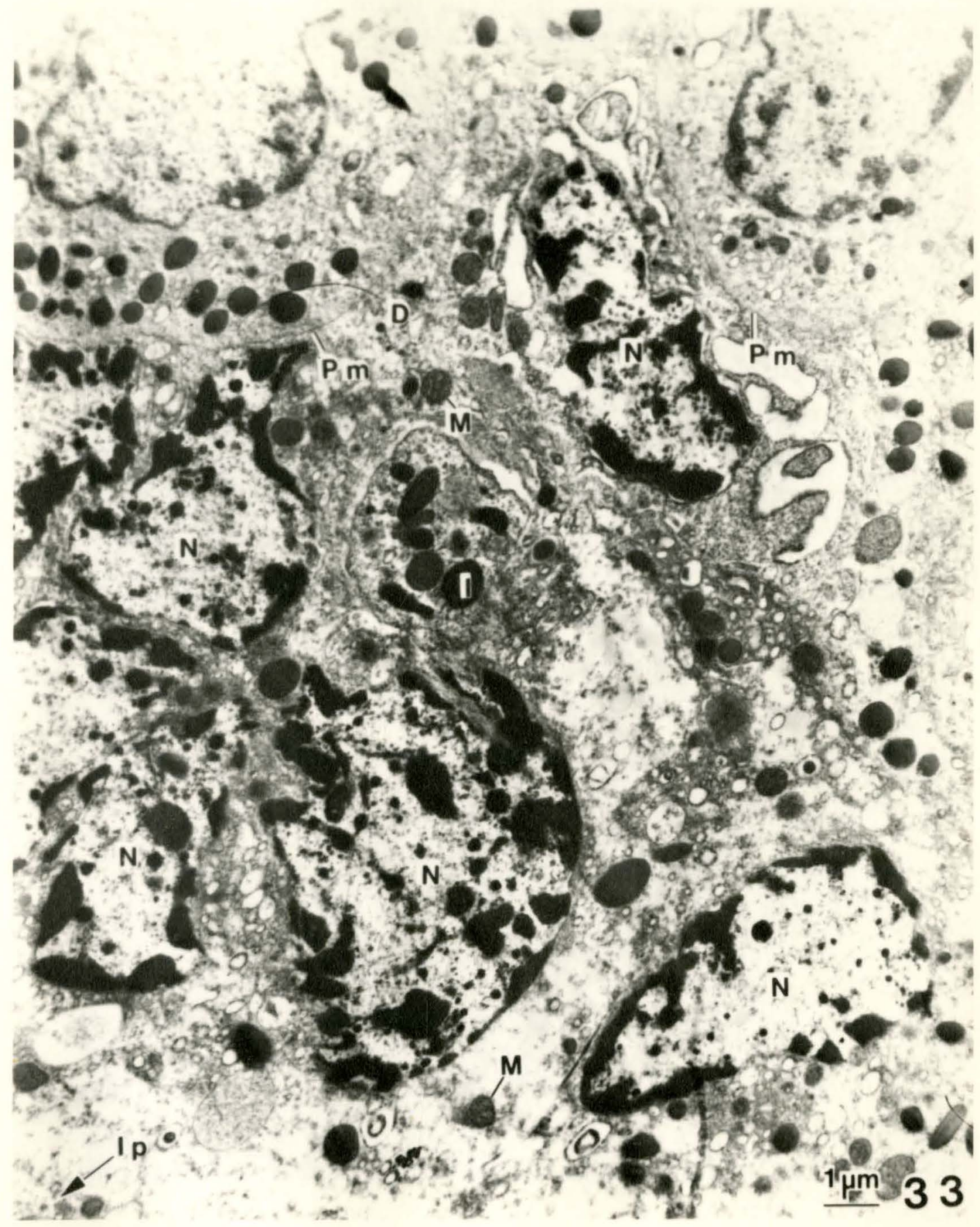


Figs. 34 and 35. Encapsulation of the nerve cord (Ip) at 24 hours. Note the layer of cellular debris (D) close to the implant. Cellular material is noted peripheral to this. L, lipid-like inclusion; $\mathrm{N}$, nuclei; $\mathrm{I}$, inclusions; $\mathrm{V}$, vacuoles; M, mitochondria. 


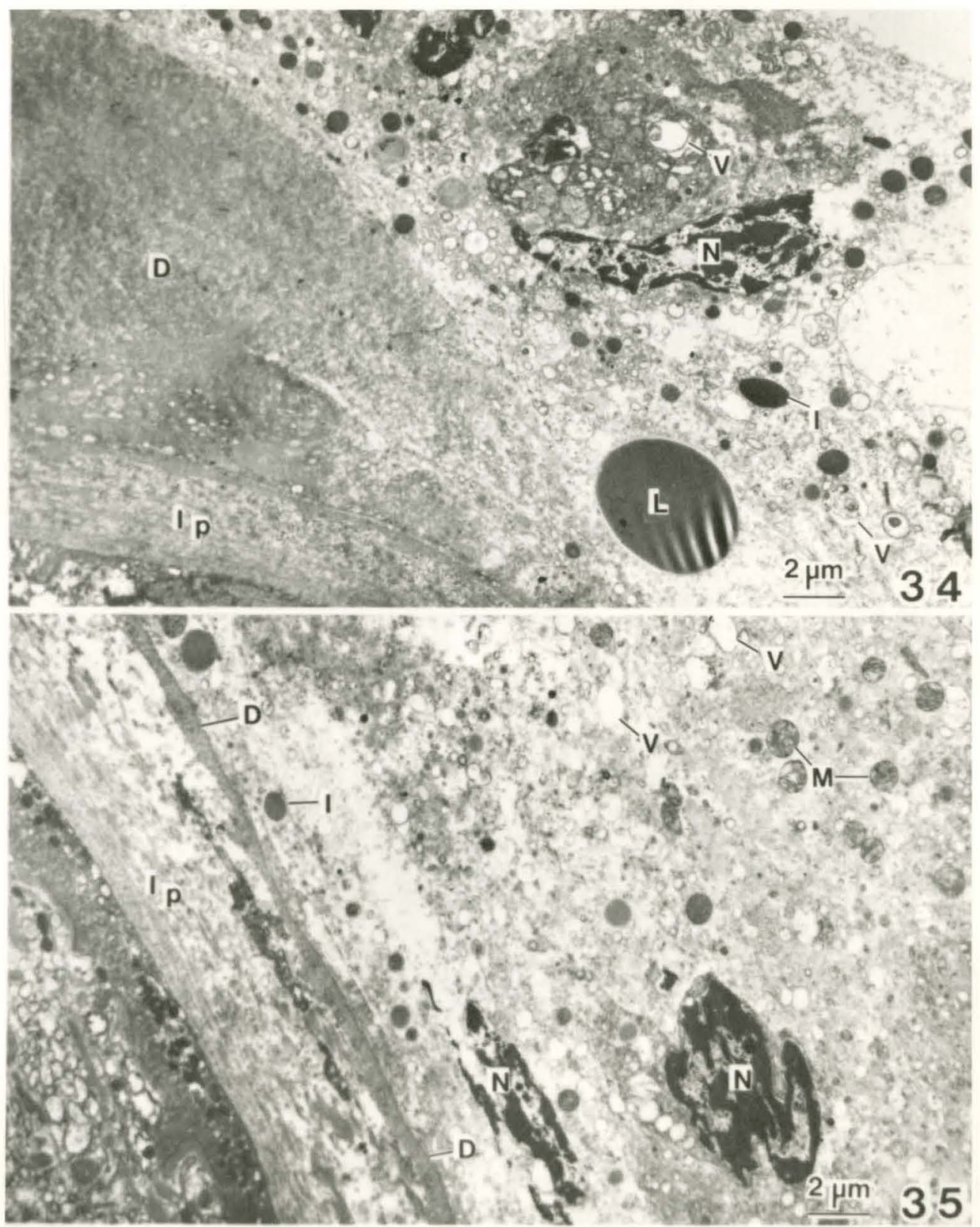


Fig.36. Encapsulation at 24 hours with the implant located at the lower left, (Ip). This material is peripheral to the cellular layers in Fig.35. No plasma membranes are readily visible, however intact nuclei (N) and inclusions (I) are identifiable.

Fig.37. Cellular layers located peripheral to that seen in Fig.36 24 hours after implantation. Plasma membranes ( $\mathrm{Pm}$ ) are easily seen in this region illustrating intact cells; $N$, nuclei. some intact cells; $N$, nuclei. 


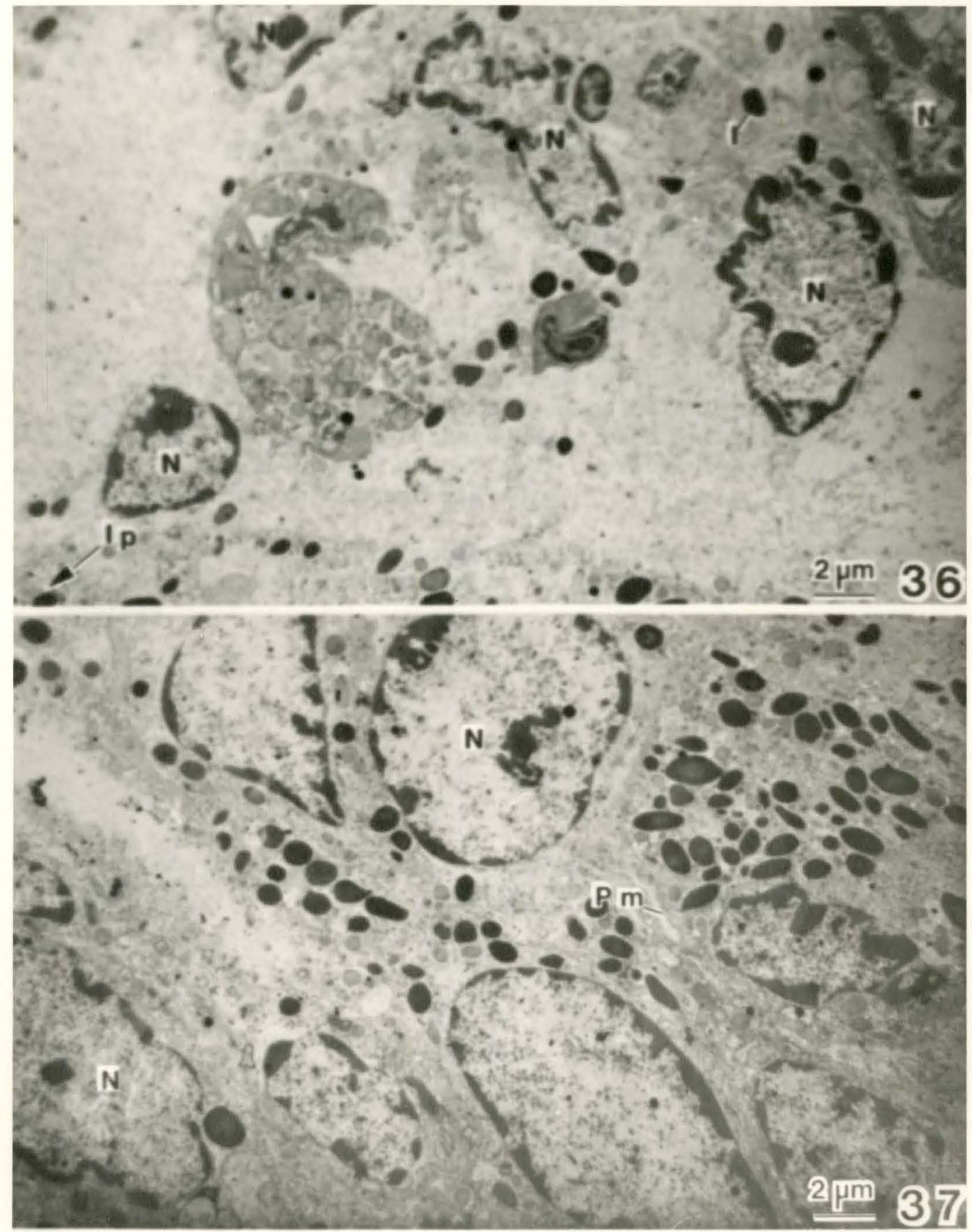




\section{APPROVAL SHEET}

the thesis submitted by Candace Ann Ennesser

has been read and approved by the following committee:

$$
\begin{aligned}
& \text { Dr. Anthony J. Nappi, Director } \\
& \text { Professor, Biology, Loyola } \\
& \text { Dr. Rosemary R. Grady } \\
& \text { Assistant Professor, Biology, Loyola } \\
& \text { Dr. John Peluso } \\
& \text { Associate Professor, Biology, Loyola }
\end{aligned}
$$

The final copies have been examined by the director of the thesis and the signature which appears below verifies the fact that any necessary changes have been incorporated and that the thesis is now given final approval by the Committe with reference to content and form.

The thesis is therefore accepted in partial fulfillment of the requirements for the degree of Master of Science in Biology.
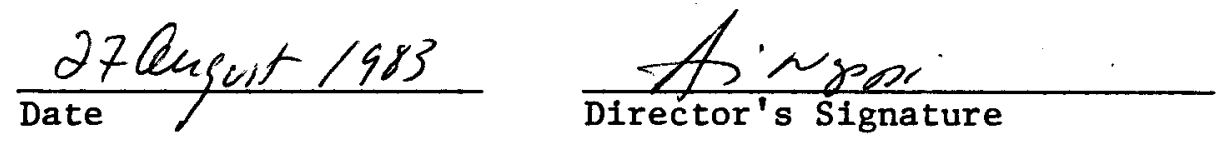